\title{
Sex Bias in Pathogenesis of Autoimmune Neuroinflammation: Relevance for Dimethyl Fumarate Immunomodulatory/Anti-oxidant Action
}

\author{
Zorica Stojić-Vukanić ${ }^{1}$ • Jelena Kotur-Stevuljević ${ }^{2}$ - Mirjana Nacka-Aleksić ${ }^{3}$. \\ Duško Kosec $^{4}$ - Ivana Vujnović ${ }^{4}$ Ivan Pilipović ${ }^{4}$ Mirjana Dimitrijevićc ${ }^{5}$. \\ Gordana Leposavić ${ }^{3}$
}

Received: 17 March 2017 / Accepted: 2 May 2017 /Published online: 22 May 2017

(C) Springer Science+Business Media New York 2017

\begin{abstract}
In the present study, upon showing sexual dimorphism in dimethyl fumarate (DMF) efficacy to moderate the clinical severity of experimental autoimmune encephalomyelitis (EAE) in Dark Agouti rats, cellular and molecular substrate of this dimorphism was explored. In rats of both sexes, DMF administration from the day of immunization attenuated EAE severity, but this effect was more prominent in males leading to loss of the sexual dimorphism observed in vehicle-administered controls. Consistently, in male rats, DMF was more efficient in diminishing the number of CD4+ T lymphocytes infiltrating spinal cord (SC) and their reactivation, the number of IL-17+ T lymphocytes and particularly cellularity of their highly pathogenic IFN- $\gamma+\mathrm{GM}-\mathrm{CSF}+$ IL-17+ subset. This was linked with changes in SC CD11b+ CD $45+\mathrm{TCR} \alpha \beta-$ microglia/proinflammatory monocyte progeny, substantiated in a more prominent increase in the
\end{abstract}

Electronic supplementary material The online version of this article (doi:10.1007/s12035-017-0595-2) contains supplementary material, which is available to authorized users.

Gordana Leposavić

gordana.leposavic@pharmacy.bg.ac.rs

1 Department of Microbiology and Immunology, Faculty of Pharmacy, University of Belgrade, 450 Vojvode Stepe, Belgrade 11221, Serbia

2 Department for Medical Biochemistry, Faculty of Pharmacy, University of Belgrade, 450 Vojvode Stepe, Belgrade 11221, Serbia

3 Department of Physiology, Faculty of Pharmacy, University of Belgrade, 450 Vojvode Stepe, Belgrade 11221, Serbia

4 Immunology Research Centre "Branislav Janković", Institute of Virology, Vaccines and Sera "Torlak", 458 Vojvode Stepe, Belgrade 11221, Serbia

5 Department of Immunology, Institute for Biological Research "Siniša Stanković", University of Belgrade, Bulevar despota Stefana 142, Belgrade 11060, Serbia frequency of anti-inflammatory phygocyting CD163+ cells and the cells expressing high surface levels of immunoregulatory CD83 molecule (associated with apoptotic cells phagocytosis and implicated in downregulation of CD4+ T lymphocyte reactivation) among $\mathrm{CD} 11 \mathrm{~b}+\mathrm{CD} 45+\mathrm{TCR} \alpha \beta$ - cells in male rat SC. These changes were associated with greater increase in the nuclear factor (erythroid-derived 2)-like 2 expression in male rats administered with DMF. In accordance with the previous findings, DMF diminished reactive nitrogen and oxygen species generation and consistently, SC level of advanced oxidation protein products, to the greater extent in male rats. Overall, our study indicates sex-specificity in the sensitivity of DMF cellular and molecular targets and encourages sex-based clinical research to define significance of sex for action of therapeutic agents moderating autoimmune neuroinflammation-/oxidative stress-related nervous tissue damage.

Keywords EAE - Dimethyl fumarate - Sexual dimorphism Pathogenic IL-17+ lymphocytes $\cdot$ CD163+ phygocyting myeloid cells $\cdot$ CD83 expression $\cdot$ Oxidative stress

\section{Introduction}

Multiple sclerosis (MS), the prototype of the autoimmune inflammatory disease of the central nervous system (CNS), is characterized by breakdown of the blood-brain barrier, autoimmune-mediated inflammation, and axonal damage [1, 2]. To date, the pathogenesis of MS has not been completely understood. The biochemical analysis of cerebrospinal fluid/blood samples and/or nervous tissue homogenates in MS [1, 3, 4] and experimental autoimmune encephalomyelitis (EAE), the principal animal model of 
MS [5-7], implicated oxidative stress in pathogenesis of EAE/MS. The damage of nervous tissue in EAE, as in MS, is linked with reactive oxygen species (ROS) and reactive nitrogen species (RNS) generation by mainly inflammatory monocyte progeny [8]. To corroborate the role of ROS and RNS in pathogenesis of autoimmune-mediated diseases is the beneficial effect of oxidative damage-reducing agents, as it is dimethyl fumarate (DMF), on the clinical MS [9-11], EAE in mice [12], and experimental autoimmune neuritis in rats [13]. The beneficial effects of DMF on the neuroinflammationassociated nervous tissue oxidative damage are ascribed to (i) direct effects of this agent on oxidative stress, through suppression of pro-oxidative cascade and activation of endogenous anti-oxidative defense system [9] and (ii) its indirect effects related to limitation of inflammation cascade [12, 14-16]. Additionally, DMF is claimed to act as an anti-inflammatory agent by activating the nuclear factor (erythroid-derived 2)-like 2 (Nrf2) pathway [9, 16, 17]. Namely, Nrf2 exerts twofold effects. It activates transcription of genes encoding many antioxidant defense enzymes, on one hand, and inhibits NF-kBmediated transcription of genes for proinflammatory mediators, on the other hand [18]. To complicate this regulation, a reciprocal effect of NF-KB on Nrf2 function is also demonstrated [19]. Moreover, it has recently been shown that DMF in both wild-type and Nrf2-/- mice immunized for EAE (i) diminishes the frequency of encephalitogenic Th1 and Th17 lymphocytes infiltrating the CNS and (ii) induces monocyte polarization towards anti-inflammatory M2 cells [12]. Hence, it has been assumed that DMF exerts beneficial effects on EAE in an Nrf2independent manner, as well [12].

Like many other autoimmune inflammatory diseases, MS is more frequent among women than men [20]. However, considering the disease progression, males are more likely to display a progressive disease, poor recovery after initial attacks, and a more malignant course, even after controlling for sex differences in the age at onset and other confounding variables [20]. Sexual dimorphism in the clinical severity of EAE has also been shown [21, 22]. In young adult Dark Agouti (DA) EAE model, which replicates early inflammatory stage of human disease, the maximum neurologic deficit and severity of disease is more pronounced in males than in age-matched females [22]. Additionally, immunopathogenic differences at the level of target organ contributing to this dimorphism have been described [22]. The latter seems to be particularly important as the clinical expression of organspecific autoimmune diseases, including EAE and MS, is largely controlled at the target organ level [23, 24]. However, despite the evidence of sex disparities in the pathogenesis and clinical outcome of EAE, the efficacy of neither immunomodulatory nor anti-oxidant drugs has been tested in this experimental model. On the other hand, although the influence of sex on effects of some immunomodulatory drugs (e.g., IFN $\beta$, glatiramer acetate, fingolimod) on clinical outcomes of the human disease has been observed, the limitation of subgroup analysis design made it difficult to draw reliable conclusions on the direction or the extent of the sexbased effects [25]. However, data on sex differences in the efficacy of anti-oxidants on MS are lacking. Finally, although the efficacy of BG12, an anti-oxidant acting also as immunomodulator, on MS was studied in two studies incorporating subjects of both sexes, no statistical tests for interaction between sex subgroups were performed [26, 27].

Having in mind the all aforementioned, the present study was undertaken to investigate if there is sex-specific influence of immunomodulatory/anti-oxidant agents on clinical outcome of EAE in DA rats. We chose DMF, an oral fumaric acid ester formulated as $B G 12$ and marketed as Tecfidera ${ }^{\circledR}$ (Biogen Idec, 2013), considering its mechanism of action. The drug has been recently approved in the USA, Australia, Canada, and the European Union as a first-line treatment for patients suffering from relapsing forms of MS. Our choice was additionally motivated by data indicating that (i) DMF metabolites identified in humans are also found in rats, and (ii) there are no sex differences in the metabolic profile of DMF when male and female rats are administered with comparable amount of this ester (European Medicines Agency 26 November 2013 EMA/800904/2013 Corr. 1 Committee for Medicinal Products for Human Use (CHMP) Assessment report: Tecfidera, http://www.ema.europa.eu/ema/index.jsp? curl=pages/medicines/human/medicines/002601/human med_001657.jsp\&mid=WC0b01ac058001d124). Indeed, in a preliminary experiment, DMF showed sex-specific efficacy in moderating the clinical outcome of immunization for EAE. Upon showing sex bias in the efficacy of DMF, the research was continued to examine putative differences in DMF influence on T lymphocyte- and myeloid cell-dependent mechanisms determining the degree of spinal cord (SC) inflammation and oxidative damage between female and male DA rats immunized for EAE.

\section{Material and Methods}

\section{Animals}

Three-month-old DA rats of both sexes were obtained from a breeding colony in the animal facility of the Immunology Research Centre "Branislav Janković" (Belgrade, Serbia). Rats were maintained under a 12-h light/dark cycle in a temperature-controlled environment. Standard laboratory food and tap water ad libitum were given throughout the duration of the experiment. All experimental procedures and animal care were performed in accordance with the Directive 2010/63/EU of the European Parliament and of the Council on the protection of animals used for scientific purposes (revising 
Directive 86/609/EEC) and approved by the Institutional Animal Care and Use Committee.

\section{EAE Induction and Evaluation}

To induce active EAE, rats were administered with $100 \mu \mathrm{L}$ of an emulsion made of equal volumes of rat SC homogenate in phosphate-buffered saline (PBS) and complete Freund's adjuvant (CFA) containing $1 \mathrm{mg} / \mathrm{mL}$ of heat-killed and dried H37Ra Mycobacterium tuberculosis (Sigma-Aldrich Chemie $\mathrm{GmbH}$, Taufkirchen, Germany) followed by an injection of $0.25 \mathrm{~mL}$ of $5 \times 10^{8}$ Bordetella pertussis (Institute of Virology, Vaccines and Sera "Torlak", Belgrade, Serbia), as previously described $[22,28]$. This immunization protocol in DA rats induces acute monophasic disease followed by full recovery of all animals. The severity of neurological deficit and body weight was recorded daily by two independent experienced observers blind to animal sex and treatment. Neurological deficit was scored as follows: 0, no clinical signs; 0.5 , distal tail atony; 1 , complete tail atony; 2 , paraparesis; 3, paraplegia; 4, tetraplegia or moribund state. None of the rats reached moribundity during the studies. For animals that developed neurological signs of EAE, mashed food and water were positioned lower to facilitate access to food and hydration and thereby to improve welfare assistance and clinical status. None of the rats experienced reduction in body weight greater than $10 \%$.

\section{Experimental Design}

Rats of both sexes were randomly assigned to either DMF treatment (+DMF groups) or vehicle ( $0.08 \%$ hydroxypropyl methylcellulose) administration (-DMF groups). DMF (100 mg/kg body weight (BW), Sigma-Aldrich Chemie $\mathrm{GmbH}$ ) in $0.08 \%$ hydroxypropyl methylcellulose was administered daily by oral gavage. The dose was chosen based on data indicating that DMF at the dose of $100 \mathrm{mg} / \mathrm{kg}$ body weight was efficient in controlling clinical signs of EAE in rats (European Medicines Agency 26 November 2013 EMA/ 800904/2013 Corr. 1 Committee for Medicinal Products for Human Use (CHMP) Assessment report: Tecfidera, http:// www.ema.europa.eu/ema/index.jsp?curl=pages/medicines/ human/medicines $/ 002601 /$ human_med_001657.jsp\&mid= WC0b01ac058001d124) and our preliminary experiment. The preliminary experiment showed that DMF at this particular dose reduces clinical signs of EAE, in a sexspecific way (Fig. 1). Control rats (-DMF groups) received a similar volume of vehicle daily by oral gavage. Considering our experience and experience of other research groups [29] indicating a high sensitivity of EAE model to stress, to minimize the impact of stress imposed by oral gavage, all rats were administered with vehicle over 3 days before the immunization for EAE. From the day of immunization, the treatment continued with vehicle or DMF until the 15 th day postimmunization (d.p.i.), when clinical signs of EAE were at the maximum (the peak of EAE). On the 15 th d.p.i., rats were sacrificed through transcardial perfusion. Prior to the perfusion, the animals were deeply anesthetized with an intraperitoneal injection of ketamine (Ketamidor, Richter Pharma AG, Wels, Austria; $100 \mathrm{mg} / \mathrm{mL}$ )/xylazine (Xylased, Bioveta, Ivanovice na Hané, Czech Republic; $20 \mathrm{mg} / \mathrm{mL}$ ) anesthetizing cocktail [80 mg/kg BW of ketamine $/ 8 \mathrm{mg} / \mathrm{kg}$ BW xylazine].

Following the perfusion, SCs were collected for (i) isolation of mononuclear cells for flow cytometry analysis (FCA) and proinflammatory and anti-inflammatory/immunomodulatory mediator/marker quantification using NO and urea assays (six rats/sex/experiment) and (ii) RT-qPCR quantification of proinflammatory and anti-inflammatory/immunomodulatory mediator/marker expression and redox status parameter measurement by biochemical analyses (six rats/sex/treatment). For biochemical analyses, SC tissue was cut into pieces and quickly frozen in liquid nitrogen and stored at $-80^{\circ} \mathrm{C}$. For each of these two sets of analyses, rats were chosen randomly, but taking care to secure that the mean maximal score was comparable between sex- and treatment-matched groups subjected to these two sets of analyzes. Prior to the perfusion blood being taken, centrifuged at $2000 \mathrm{~g}$ for $15 \mathrm{~min}$ at $4{ }^{\circ} \mathrm{C}$ to obtain plasma for redox status analyses (six rats/sex/experiment). Plasma was stored at $-80^{\circ} \mathrm{C}$ until assayed.

\section{Antibodies and Immunoconjugates}

For immunolabeling, the following monoclonal antibodies (mAbs) were used: phycoerythrin (PE)-conjugated mouse anti-rat CD4 (clone OX-38), biotin-conjugated mouse anti-rat CD134 (clone OX-40), PE-conjugated mouse anti-rat ED2 (CD163; clone HIS36), biotin-conjugated mouse anti-rat CD45 (clone OX-1), PE-conjugated rat anti-mouse IL-17A (clone TC11-18H10), fluorescein isothiocyanate (FITC)-conjugated mouse anti-rat IFN- $\gamma$ (clone DB-1), peridinin-chlorophyll protein (PerCP)-conjugated mouse anti-rat $\operatorname{TCR} \alpha \beta$ (clone R73). All these mAbs were purchased from BD Biosciences, San Jose, CA, USA. In immunophenotyping, the following mAbs were also included: Alexa Fluor ${ }^{\circledR}$ 647-conjugated antirat $\mathrm{TCR} \alpha \beta$ (clone R73, Biolegend, San Diego, CA, USA); FITC-conjugated mouse anti-rat CD11b (clone OX-42, Serotec, Oxford, UK); goat polyclonal anti-rat CD83 (Santa Cruz Biotechnology, Inc., Dallas, TX, USA); and Alexa Fluor $®$ 647-conjugated mouse anti-rat GM-CSF (clone 83308, Novus Biologicals, Littleton, CO, USA). As secondary step reagents, PerCP Streptavidin (BD Biosciences) and PE-conjugated donkey anti-goat IgG (Santa Cruz Biotechnology, Inc.) were used. 


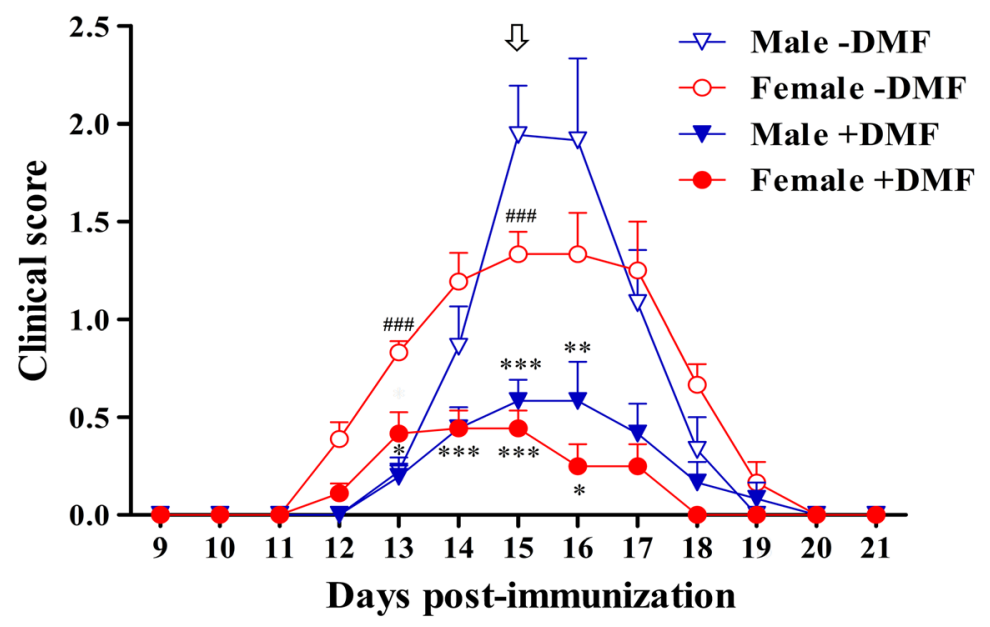

\begin{tabular}{|c|c|c|c|c|c|}
\hline & Incidence & $\begin{array}{l}\text { EAE onset } \\
\text { (d.p.i.) }\end{array}$ & $\begin{array}{c}\text { Duration } \\
\text { (days) }\end{array}$ & $\begin{array}{c}\text { Maximum } \\
\text { clinical score }\end{array}$ & Severity index \\
\hline \multicolumn{6}{|c|}{ Experiment 1} \\
\hline \multicolumn{6}{|c|}{ Female } \\
\hline -DMF & $6 / 6$ & $12.5 \pm 0.22 \#$ & $5.8 \pm 0.30$ & $1.3 \pm 0.21 \#$ & $0.96 \pm 0.133$ \#\# \\
\hline +DMF & $4 / 6$ & $13.0 \pm 0.41$ & $4.5 \pm 0.28 *$ & $0.6 \pm 0.13 *$ & $0.58 \pm 0.075 *$ \\
\hline \multicolumn{6}{|l|}{ Male } \\
\hline -DMF & $5 / 6$ & $13.8 \pm 0.37$ & $4.8 \pm 0.48$ & $2.4 \pm 0.24$ & $1.54 \pm 0.109$ \\
\hline +DMF & $4 / 6$ & $13.8 \pm 0.48$ & $5.8 \pm 0.70$ & $0.9 \pm 0.13^{* *}$ & $0.70 \pm 0.067 * * *$ \\
\hline \multicolumn{6}{|c|}{ Experiment 2} \\
\hline \multicolumn{6}{|c|}{ Female } \\
\hline -DMF & $12 / 12$ & $12.4 \pm 0.15$ & & $1.3 \pm 0.21 \# \#$ & \\
\hline +DMF & $8 / 12$ & $13.1 \pm 0.23$ & & $0.7 \pm 0.09 *$ & \\
\hline \multicolumn{6}{|l|}{ Male } \\
\hline -DMF & $10 / 12$ & $13.7 \pm 0.26$ & & $2.3 \pm 0.14$ & \\
\hline +DMF & $8 / 12$ & $13.6 \pm 0.32$ & & $0.9 \pm \mathbf{0 . 0 8} * * *$ & \\
\hline
\end{tabular}

Fig. 1 DMF reduced the maximum clinical score and severity index of EAE in rats of both sexes leading to the loss of the sexual dimorphism. In female and male rats, active EAE was induced by injection of rat spinal cord (SC) homogenate in complete Freund's adjuvant. Rats subjected to the immunization were administered with $100 \mathrm{mg} / \mathrm{kg}$ BW of DMF (+DMF) or vehicle (-DMF) by oral gavage, daily, from the day of immunization. To minimize stress induced by oral gavage, all animals were pretreated with vehicle for 3 days before the immunization. The neurological signs of EAE were scored for 21 (experiment 1 ) or 15 days (experiment 2 ) as described in "Material and Methods." Line graph indicates the daily mean clinical score \pm S.E.M for - DMF and + DMF female and male rats combined from experiments 1 and. Please note that 12 out of $18 \mathrm{rats} / \mathrm{sex} /$ treatment were sacrificed at the peak of the disease (white arrow) for spinal cord analyses

\section{Isolation of Mononuclear Cells}

To obtain single-cell mononuclear cell suspensions, SC tissue was meshed through $70-\mu \mathrm{m}$ nylon cell strainer (BD Biosciences, Erembodegem, Belgium) submerged in ice-cold RPMI 1640 medium supplemented with 5\% fetal calf serum (FCS). Thereby obtained single-cell suspensions were then fractioned on a discontinuous $40 / 70 \%$ Percoll gradient at $1000 \times g$ for $50 \mathrm{~min}$. Mononuclear cells from the interface were collected and counted using an improved Neubauer hemocytometer. (experiment 2). The incidence, the day of neurological sign appearance (onset), duration of the clinical disease (duration), maximum clinical score (calculated by adding maximum scores of individual diseased rats and divided by the number of diseased rats), and severity index (calculated by dividing the cumulative clinical scores by the number of days with clinical signs of EAE) of EAE are presented as means \pm S.E.M in the table. Experiment 1: Two-way ANOVA showed significant interaction between the effects of treatment and sex for the maximum clinical score $\left(F_{(1,15)}=5.166 ; p \leq 0.05\right)$ and severity index $\left(F_{(1,15)}=5.214 ; p \leq 0.05\right)$. Experiment 2: Two-way ANOVA showed significant interaction between the effects of treatment and sex for the maximum clinical score $\left(F_{(1,34)}=6.28 ; p \leq 0.05\right)$. \#p $\leq 0.05 ; \# p \leq 0.01$; \#\# $\leq 0.001$; \#Female vs Male; $* \leq 0.05 ; * * \leq 0.01 ; * * * p \leq 0.001 ; *+$ DMF vs sex-matched - DMF

\section{Cell Staining and FCA}

\section{Surface and Intracellular Antigen Immunostaining}

For analyses of surface antigen expression, cells were incubated with saturating concentrations of either fluorochrome-labeled $\mathrm{mAbs}$ or biotin-conjugated/unconjugated $\mathrm{Abs}$ for $30 \mathrm{~min}$ and washed in PBS supplemented with $2 \%$ FCS and $0.1 \% \mathrm{NaN}_{3}$ (FACS buffer). When biotin-conjugated/unconjugated Abs were applied, cells were incubated with appropriate second-step reagents for additional $30 \mathrm{~min}$, washed, and collected for FCA. 
To determine cell apoptosis, after surface labeling to identify CD4+TCR $\alpha \beta+$ lymphocytes, SC cells were washed with PBS and then with Annexin V binding buffer (BD Pharmingen). After washing, the cells were incubated with $5 \mu \mathrm{L}$ of Annexin V-FITC (BD Pharmingen) for $15 \mathrm{~min}$ at room temperature in the dark and collected for FCA [28].

For cytokine production analyses, freshly isolated SC cells were cultured in 24-well plates (Sarstedt AG \& Co., Nümbrecht, Germany) at a concentration of $10^{6}$ cells $/ \mathrm{mL}$ in culture medium supplemented with $200 \mathrm{ng} / \mathrm{mL}$ phorbol 12-myristate 13-acetate (PMA, Sigma-Aldrich Chemie $\mathrm{GmbH}$ ) and $400 \mathrm{ng} / \mathrm{mL}$ ionomycin (Sigma-Aldrich Chemie $\mathrm{GmbH}$ ) and $3 \mu \mathrm{g} / \mathrm{mL}$ of brefeldin A (eBioscience). The culture medium consisted of RPMI 1640 supplemented with $2 \mathrm{mM}$ L-glutamine (Serva, Heidelberg, Germany), $1 \mathrm{mM}$ sodium pyruvate (Serva), 100 units/mL penicillin (ICN, Costa Mesa, CA, USA), $100 \mu \mathrm{g} / \mathrm{mL}$ streptomycin (ICN), and 10\% FCS (Gibco, Grand Island, NY, USA). The plates were incubated in humidified atmosphere of $5 \% v / v \mathrm{CO}_{2}$ for $4 \mathrm{~h}$ at $37{ }^{\circ} \mathrm{C}$. Following incubation, the cells were harvested and subjected to cell surface antigen immunostaining. Following staining for surface antigen detection, the cells were washed and fixed/permeabilized overnight at $4{ }^{\circ} \mathrm{C}$, using the solutions from fixation/ permeabilization buffer kit (eBioscience; http://www. ebioscience.com/resources/best-protocols/flow-cytometryprotocols.htm). Next, the cells were washed using appropriate permeabilization buffer (eBioscience), incubated with fluorochrome-conjugated anti-IFN- $\gamma /$ anti-IL-17/anti-GM-CSF $\mathrm{mAb}$ cocktails for $30 \mathrm{~min}$ at room temperature in the dark, and then washed again and collected for FCA.

\section{FCA}

For FCA, 50,000 cellular events per sample were acquired on a FACSVerse flow cytometer (Becton Dickinson, Mountain View, CA, USA) using FACSuite v1.0.5.3841 software (Becton Dickinson). FlowJo software version 7.8. (TreeStar Inc., Ashland, OR, USA) was used to analyze the data for percentage of markerpositive cells and mean fluorescence intensity (MFI). Dead cells and debris were excluded from the analyses by selective gating based on forward scatter (FSC) and side scatter (SSC), whereby background staining level for each fluorochrome type was defined using nonspecific IgG isotype-matched controls. Fluorescence minus one (FMO) controls were applied to set gating boundaries [28]. For setting cutoff for Annexin V staining, apart from negative (unstained cells) control, positive biological comparison control (lymphocytes treated with $10 \% v / v$ dimethyl sulfoxide for $60 \mathrm{~min}$ at $37{ }^{\circ} \mathrm{C}$ ) was used.

\section{RT-qPCR Quantification of Inducible Nitric Oxide Synthase, Arginase, and Cytokine mRNAs}

SC tissue samples were harvested using nucleic acid purification lysis solution (Applied Biosystems, Foster City, CA, USA) and immediately stored at $-70{ }^{\circ} \mathrm{C}$ until RNA purification. Total RNA from SC tissue homogenates was extracted using ABI Prism 6100 Nucleic Acid PrepStation system (Applied Biosystems) and Total RNA Chemistry Starter Kit (Applied Biosystems). The procedure included DNAse treatment to ensure that no genomic DNA contamination was present. Isolated RNA was converted to complementary DNA (cDNA) using High Capacity cDNA Reverse Transcription Kit (Applied Biosystems), in 20- $\mu \mathrm{L}$ reactions ran under optimal conditions $\left(10 \mathrm{~min}, 25^{\circ} \mathrm{C} ; 120 \mathrm{~min}\right.$, $37{ }^{\circ} \mathrm{C} ; 5 \mathrm{~s}, 85^{\circ} \mathrm{C}$ ). For analysis of inducible nitric oxide synthase (iNOS), arginase, heme oxygenase 1 (HO-1), nuclear factor, erythroid 2-like 2 (Nrf2) and cytokines (IL-1 $\beta$ and IL-6) messenger RNA (mRNA) expression, triplicate 25- $\mu$ L RT-qPCR reactions, containing $1 \times$ TaqMan Gene Expression Master Mix (Applied Biosystems), $1 \times$ mix of premade primer and hydrolysis probe sets (TaqMan Gene Expression Assays, Applied Biosystems), and $5 \mu \mathrm{L}$ of cDNA template, were ran under the default Applied Biosystems 7500 Real-Time PCR System conditions $\left(2 \mathrm{~min}\right.$ at $50{ }^{\circ} \mathrm{C}, 10 \mathrm{~min}$ at $95^{\circ} \mathrm{C}$, followed by 40 cycles consisting of $15 \mathrm{~s}$ at $95^{\circ} \mathrm{C}$ and $1 \mathrm{~min}$ at $60^{\circ} \mathrm{C}$ incubations each). The following gene expression assays were used: iNOS (Nos2; Rn00561646_m1), arginase (Arg-1; Rn00691090_m1), HO-1 (decycling) 1 (Hmox 1; Rn00561387_m1), Nrf2 (Nrf2, also called Nfe212; Rn00582415_m1), IL-1 $\beta$ (Il1b; Rn99999009_m1), IL-6 (I16; Rn99999011_m1), and $\beta$-actin (Actb; Rn00667869_m1). Relative quantification of mRNA level was done using SDS v1.4.0. software (Applied Biosystems) and $2^{-\Delta \Delta C t}$ method with $\beta$-actin as a normalizer.

\section{NO Production and Arginase Activity in SC Mononuclear Cells}

Mononuclear cells retrieved from SC $\left(1 \times 10^{5} /\right.$ well $)$ were cultured in 96-well plates in RPMI 1640 supplemented with $5 \% \mathrm{FCS}$ overnight at $37{ }^{\circ} \mathrm{C}$ in a humidified 5\% v/v $\mathrm{CO}_{2}$ atmosphere. Supernatants were assayed for the level of NO by Griess reagent, as previously described [30]. The concentration of nitrite in the samples was calculated using a $\mathrm{NaNO}_{2}(1-80 \mu \mathrm{M})$ as a standard. The cells were collected and processed for arginase activity by the method based on the urea production as previously described [29]. The concentration of urea in the samples was calculated according to the standard curve (1-80 $\mu \mathrm{M}$ of urea). 


\section{Analyses of Redox Status}

For biochemical analyses of redox status, frozen SC tissue was diluted 10 times in $0.1 \mathrm{M}$ phosphate buffer ( $\mathrm{pH} 7.4$, supplemented with $11.5 \mathrm{mg} / \mathrm{mL} \mathrm{KCl}$ ), homogenized using a homogenizer (Thomas Scientific, Swedesboro, NJ, USA) and centrifuged at $12,000 \mathrm{~g}$ for $40 \mathrm{~min}$. Thereby obtained supernatants were used for analyses. All the steps were carried out at $0-4{ }^{\circ} \mathrm{C}$. The level of $\mathrm{O}_{2}{ }^{--}$was estimated according to the rate of yellow nitroblue tetrazolium reduction to blue diformazan [31].

Xanthine oxidase (XO) was determined spectrophotometrically by using the rate of urate formation from hypoxanthine measuring absorbance increase at $290 \mathrm{~nm}$ as previously described [7]. A unit of activity is defined as forming of $1 \mu \mathrm{M}$ of urate per minute at $25^{\circ} \mathrm{C}$.

$\mathrm{Cu} / \mathrm{Zn}$ superoxide dismutase (SOD) activity was measured using slightly modified method of Misra and Fridovich [32], based on the ability of SOD to inhibit auto-oxidation of epinephrine in alkaline medium. The enzyme activity is calculated as percentage of inhibition of epinephrine auto-oxidation [7].

Glutathione (GSH) concentration was assayed according to its reaction with 5,5'-dithiobis-2-nitrobenzoic acid [7]. Spectrophotometric determination of a yellow complex 5thio-2-nitrobenzoate at $412 \mathrm{~nm}$ was performed after the deproteinization with sulfosalicylic acid. Reduced glutathione in a range from 0.5 to $2 \mu \mathrm{mol} / \mathrm{L}$ was used for the calibration.

Malondialdehyde (MDA) concentration was measured using the thiobarbituric acid-reactive substance (TBARS) assay employing the molar absorption coefficient of $1.56 \times 10^{5} \mathrm{M}^{-1} \mathrm{~cm}^{-1}$ and spectrophotometry at $535 \mathrm{~nm}$ [33].

Advanced oxidation protein products (AOPP) concentration was assayed by measuring the absorbance at $340 \mathrm{~nm}$ of complex formed in its reaction with glacial acetic acid potassium-iodide [34]. Chloramine T, a compound exhibiting specific absorption maximum at $340 \mathrm{~nm}$, was used as a standard with concentration range from 10 to $100 \mu \mathrm{mol} / \mathrm{L}$.

Total pro-oxidant capacity (TOC) was measured by a spectrophotometric method introduced by Erel [35] and slightly modified in our laboratory [36]. The method is based on the ability of all oxidants such as hydrogen peroxide and lipid hydroperoxide to oxidize the ferrous ion-o-dianisidine complex to ferric ion. Second reaction relies on the ferric ion reaction with xylenol orange in an acidic medium, which makes a colored complex. The intensity of color is proportional with the total amount of oxidant molecules present in the sample. The assay is calibrated with hydrogen peroxide in concentration ranged from 10 to $200 \mu \mathrm{mol} / \mathrm{L}$.

Total anti-oxidant capacity (TAC) was measured by a spectrophotometric method using $10 \mathrm{mmol} / \mathrm{L}$ colored 2,2'azinobis-(3-ethylbenzothiazoline-6-sulfonic acid radical cation $\left(\operatorname{ABTS}\left(*^{+}\right)\right)$as a chromogen [37]. The $\operatorname{ABTS}\left(*^{*}\right)$ is decolorized by anti-oxidants according to their concentrations and anti-oxidant capacities. This change in color is measured as a change in absorbance at $660 \mathrm{~nm}$. The reaction is calibrated with Trolox, vitamin E water-soluble analog, and the assay results are expressed in micromoles Trolox equivalent/L.

Pro-oxidant-anti-oxidant balance (PAB) was determined by a modified PAB test using $0.6 \%$ 3,3',5,5'-tetramethylbenzidine (TMB) in dimethyl sulfoxide as a chromogen [7, 38]. PAB test measures $\mathrm{H}_{2} \mathrm{O}_{2}$ concentration in an anti-oxidant environment, because TMB could react at the same time with $\mathrm{H}_{2} \mathrm{O}_{2}$ (reaction catalyzed with peroxidase enzyme), so as with reductive substances such as uric acid (chemical, non-catalyzed reaction). Enzymatic reaction causes TMB oxidation to blue product, whereas chemical reduction leads to non-colored product. The net reaction is exactly the difference between two opposite oxido-reductive processes at the same substrate. Reaction calibration is performed with the mixture of $\mathrm{H}_{2} \mathrm{O}_{2}$ and uric acid in different ratios, defined from 0 to $100 \%$.

Biochemical parameters in SC tissue were normalized per gram protein in the sample [39]. Spectrophotometric assays were performed with a continuous spectrophotometer (Pharmacia LKB, Cambridge, UK) with the exception of assays for determination of TAC and TOC which were implemented on ILAB 300 Plus analyzer (Instrumentation Laboratory, Milan, Italy).

\section{Statistical Analysis}

The quantitative data were analyzed by two-way ANOVA (treatment $\times$ sex) followed by Bonferroni as post hoc test. Data were presented as mean \pm S.E.M. All statistical analyses were performed using GraphPad Prism 5 software (GraphPad Software, Inc., La Jolla, CA, USA). Values of $p \leq 0.05$ were considered significant.

\section{Results}

\section{DMF was more Efficient in Reducing the Severity of EAE in Males}

As shown in the preliminary experiment (experiment 1), when the neurological signs of EAE were followed until the 21st d.p.i. (Fig. 1), irrespective of treatment, rats of both sexes immunized for EAE developed monophasic self-limiting disease. The incidence of the disease was higher in female than male -DMF rats in experiment 1 , and in subsequent experiment (experiment 2) performed to examine immunological and oxidative stress parameters in SC at the peak of EAE (Fig. 1). In both the experiments, the first neurological signs of EAE appeared later $(p \leq 0.05$ and $p \leq 0.001$ in experiments 1 and 2, respectively) in male than in female -DMF rats. Besides, the symptomatic stage of the disease was of shorter 
duration in male when compared with female -DMF rats, but this difference did not reach statistical significance (Fig. 1). However, the maximum neurological deficit was greater ( $p \leq 0.05$ and $p \leq 0.001$ in experiments 1 and 2 , respectively) in male than in female -DMF rats (Fig. 1). The clinical severity index calculated by dividing the cumulative clinical scores by the number of days with clinical signs of EAE [40] also suggested more severe $(p \leq 0.01)$ disease in male $-\mathrm{DMF}$ rats than in their female counterparts (Fig. 1).

Oral application of DMF diminished the incidence of EAE in both female and male rats, so in both the experiments, it did not significantly differ between sexes (Fig. 1). However, irrespective of sex, DMF did not influence the appearance of the first neurological signs of EAE (Fig. 1). DMF reduced $(p \leq 0.05)$ the duration of the clinical disease in female rats, whereas it was ineffective in this respect in their male counterparts (Fig. 1). Consequently, the duration of clinical disease was comparable in female and male +DMF rats (Fig. 1). In both the experiments, DMF attenuated the maximum neurological deficit in female $(p \leq 0.05)$ and male rats $(p \leq 0.01$ and $p \leq 0.001$ in experiments 1 and 2 , respectively), but to a greater extent in males (Fig. 1). Thus, the maximum neurological deficit did not significantly differ between female and male $+\mathrm{DMF}$ rats (Fig. 1). Additionally, judging by the clinical severity index, DMF reduced the severity of EAE in both female $(p \leq 0.05)$ and male $(p \leq 0.001)$ rats, abolishing the sexual dimorphism observed in - DMF rats (Fig. 1).

\section{Sexually Dimorphic \\ Immunomodulatory/Anti-inflammatory Effects of DMF in $\mathbf{E A E}$}

\section{DMF was more Efficient in Diminishing Number and Reactivation of CD4+ T Lymphocytes Infiltrating SC of Male than Female Rats Immunized for EAE}

At the peak of EAE, in accordance with the greater maximum neurological deficit, more $(p \leq 0.05)$ mononuclear cells were retrieved from SC of male $\left(3.63 \times 10^{6} \pm 0.09 \times 10^{6}\right)-\mathrm{DMF}$ rats compared with their female counterparts $\left(2.70 \times 10^{6} \pm 0.06 \times 10^{6}\right)$, and among them was found more $(p \leq 0.001) \mathrm{CD} 4+\mathrm{T}$ lymphocytes, the major drivers of EAE development in rodents immunized with CNS antigen(s) in CFA [41] (Fig. 2a). Irrespective of sex, DMF diminished $(p \leq 0.001)$ the number of mononuclear cells isolated from female $\left(2.09 \times 10^{6} \pm 0.08 \times 10^{6}\right)$ and male $\left(1.97 \times 10^{6} \pm 0.88 \times 10^{6}\right)$. Additionally, fewer $(p \leq 0.001)$ CD4+ T lymphocytes were recovered from +DMF compared with sex-matched - DMF rats, but this effect of DMF was more prominent in males (Fig. 2a). Consequently, CD4+ T lymphocyte number was comparable in SC mononuclear cell suspensions from female and male +DMF rats (Fig. 2a).
Next, the expression of CD134 on CD4+TCR $\alpha \beta+$ lymphocytes was examined. This molecule was used as a marker of CD4+ T lymphocyte reactivation based on findings indicating that encephalitogenic effector CD4+ T lymphocytes down-regulate its expression before crossing the blood-brain barrier [42]. The frequency of re-activated CD134+ cells among CD4+ TCR $\alpha \beta+$ lymphocytes $(p \leq 0.01)$, and CD134 surface density (judging by CD134 MFI) $(p \leq 0.001)$, were higher in male compared with female $-\mathrm{DMF}$ rats (Fig. 2b). Irrespective of sex, DMF diminished $(p \leq 0.001)$ not only the frequency of CD134+ cells among CD4+ TCR $\alpha \beta+$ lymphocytes but also CD134 surface density on CD4+TCR $\alpha \beta+$ lymphocytes, judging by CD134 MFI (Fig. 2b). The latter effect was more prominent in males than in females, leading to the loss of the sexual dimorphism observed in -DMF rats (Fig. 2b).

Considering the previous findings and proapoptotic influence of DMF on purified human T lymphocytes [43], CD4+ T lymphocytes were also investigated for the frequency of apoptotic Annexin $\mathrm{V}+$ cells. Their frequency was lower $(p \leq 0.001)$ in male compared with female -DMF rats (Fig. 2c). Contrary to expectations, irrespective of sex, DMF did not significantly influence the frequency of Annexin $\mathrm{V}+$ cells among CD4+TCR $\alpha \beta+$ lymphocytes (Fig. 2c).

\section{DMF was more Efficient in Diminishing the Frequency

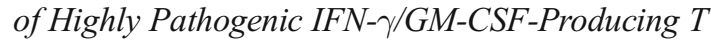 Lymphocytes in SC of Male Rats Immunized for EAE}

Having in mind that DMF diminishes the frequencies of pathogenic T lymphocytes producing IL-17 (IL-17+) in mouse EAE model [12], their frequency in PMA- and ionomycinstimulated $\mathrm{T}$ lymphocytes isolated from SC was examined. At the peak of EAE, IL-17+ cell frequency and number within $\mathrm{T}$ lymphocytes were higher $(p \leq 0.001)$ in $\mathrm{SC}$ from male compared with female - DMF rats (Fig. 3a). DMF reduced $(p \leq 0.001)$ their frequency and number in rats of both sexes (Fig. 3a). However, this effect of DMF was more prominent in males, so IL-17+ cell frequency among $\mathrm{T}$ lymphocytes and their number did not significantly differ between female and male + DMF rats (Fig. 3a).

Next, considering several findings, IL-17+ T lymphocytes were examined for their cytokine profile. Namely, IL-17+ CD4+ T lymphocytes are shown to exhibit a great degree of context-dependent plasticity, so they are capable of coproducing IFN- $\gamma$ and GM-CSF [44-46]. Additionally, IFN- $\gamma$ - and GM-CSF-producing (IFN- $\gamma+\mathrm{GM}-\mathrm{CSF}+$ ) IL-17+ $\mathrm{T}$ cells are found to be highly pathogenic in mouse EAE models [44, 45] and positively correlated with severity of neurological deficit in DA rat EAE model [22]. In accordance with more severe neurological deficit, both the frequency of IFN- $\gamma+$ GM-CSF+ cells among IL-17+ T lymphocytes and their number were higher $(p \leq 0.001)$ in male than in female - DMF rat SC (Fig. 3b). In rats of both sexes, DMF diminished 
Fig. 2 DMF was more efficient in decreasing the number of CD4+ T lymphocytes infiltrating spinal cord of male rats immunized for EAE. Flow cytometry dot plots show a CD4 vs TCR $\alpha \beta$ staining of mononuclear cells (MNC) retrieved at the peak of EAE from spinal cord (SC) of female and male rats administered with DMF (+DMF) or vehicle (-DMF) and b CD134 and c Annexin V staining of $\mathrm{CD} 4+\mathrm{TCR} \alpha \beta+$ lymphocytes gated as shown (a). Scatter plots present a the number of CD4+TCR $\alpha \beta+$ lymphocytes and the frequency of $\mathbf{b}$ CD134+ and c Annexin V+ cells among CD4+TCR $\alpha \beta+$ cells in SC from female and male $+\mathrm{DMF}$ and -DMF rats. b Numbers in the table represent CD134 mean fluorescence intensity (MFI) on CD134+CD4+ TCR $\alpha \beta+$ cells. Results are from one of two similar experiments each comprising six rats/group. Data are presented as mean \pm S.E.M. Two-way ANOVA showed significant interaction between the effects of treatment and sex for CD4+TCR $\alpha \beta+$ lymphocyte number $\left(F_{(1,20)}=58.72\right.$; $p \leq 0.001)$ and CD134 MFI $\left(F_{(1,20)}=13.95 ; p \leq 0.01\right)$. $* * p \leq 0.01 ; * * * p \leq 0.001 ;{ }^{\mathrm{a}}$ Male vs female; ${ }^{b}+$ DMF vs sexmatched-DMF
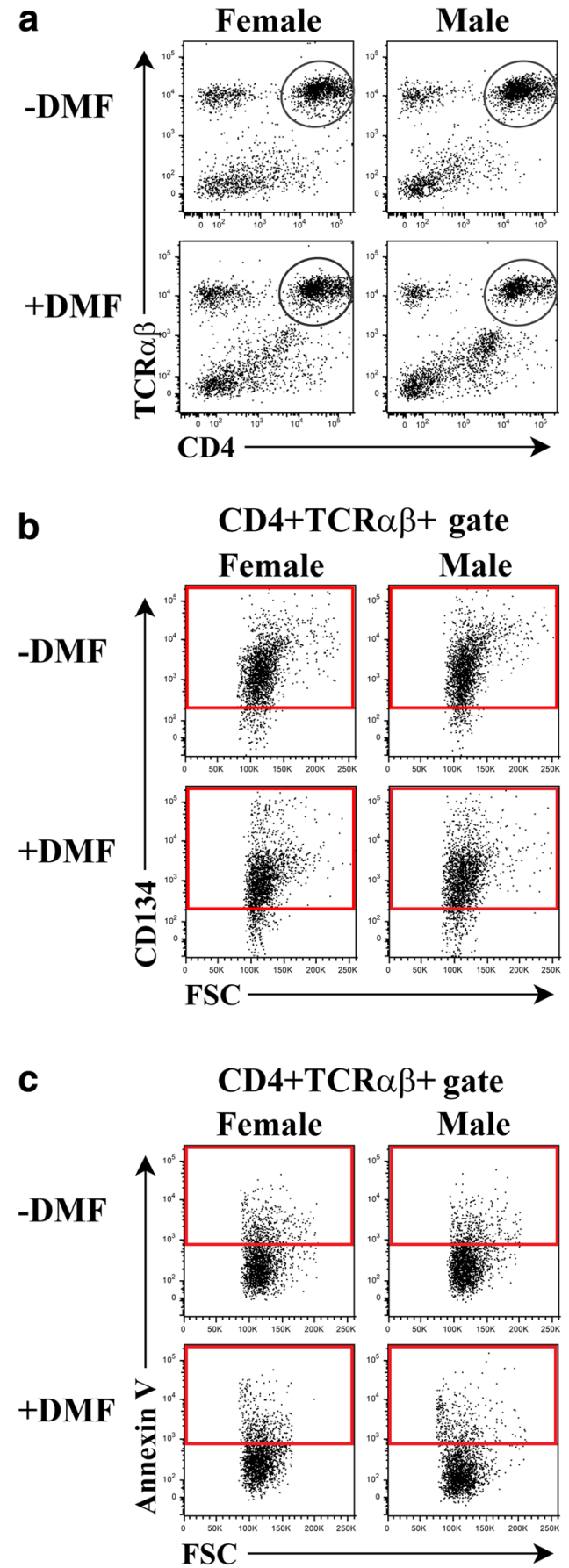
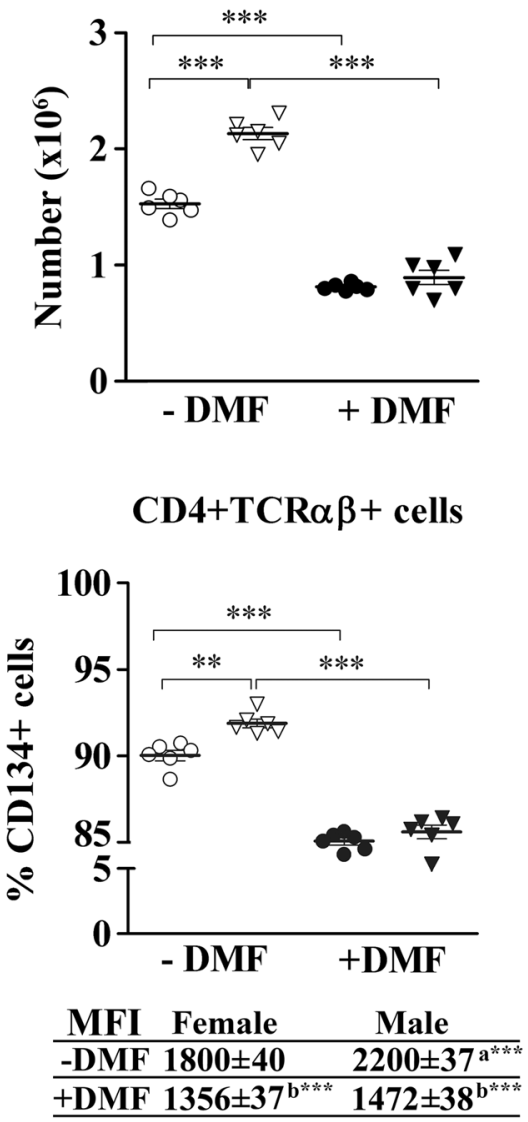

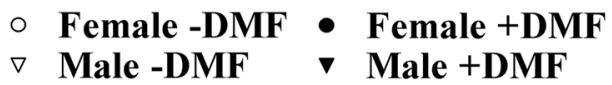

the frequency of IFN- $\gamma+$ GM-CSF+ cells among IL-17+ T lymphocytes ( $p \leq 0.05$ and $p \leq 0001$ in female and male rats, respectively) and their number $(p \leq 0.001)$ in SC (Fig. 3b). These DMF effects were more pronounced in male rats than in their female counterparts. Consequently, we failed to find any significant sex differences in either the frequency of IFN- $\gamma+$ GM-CSF+ cells among IL-17+ T lymphocytes from SC of
+ DMF rats or in their number (Fig. 3b). Given that IL-1 $\beta$ and IL- 6 have been implicated in differentiation of pathogenic IFN- $\gamma+\mathrm{GM}-\mathrm{CSF}+$ cells [47], their expression in SC tissue was also examined. In agreement with the higher frequency of IFN- $\gamma+$ GM-CSF+ cells among IL-17+ T lymphocytes from male compared with female -DMF rats, IL- $1 \beta$ mRNA expression was upregulated $(p \leq 0.001)$ in their $\mathrm{SC}$, whereas 

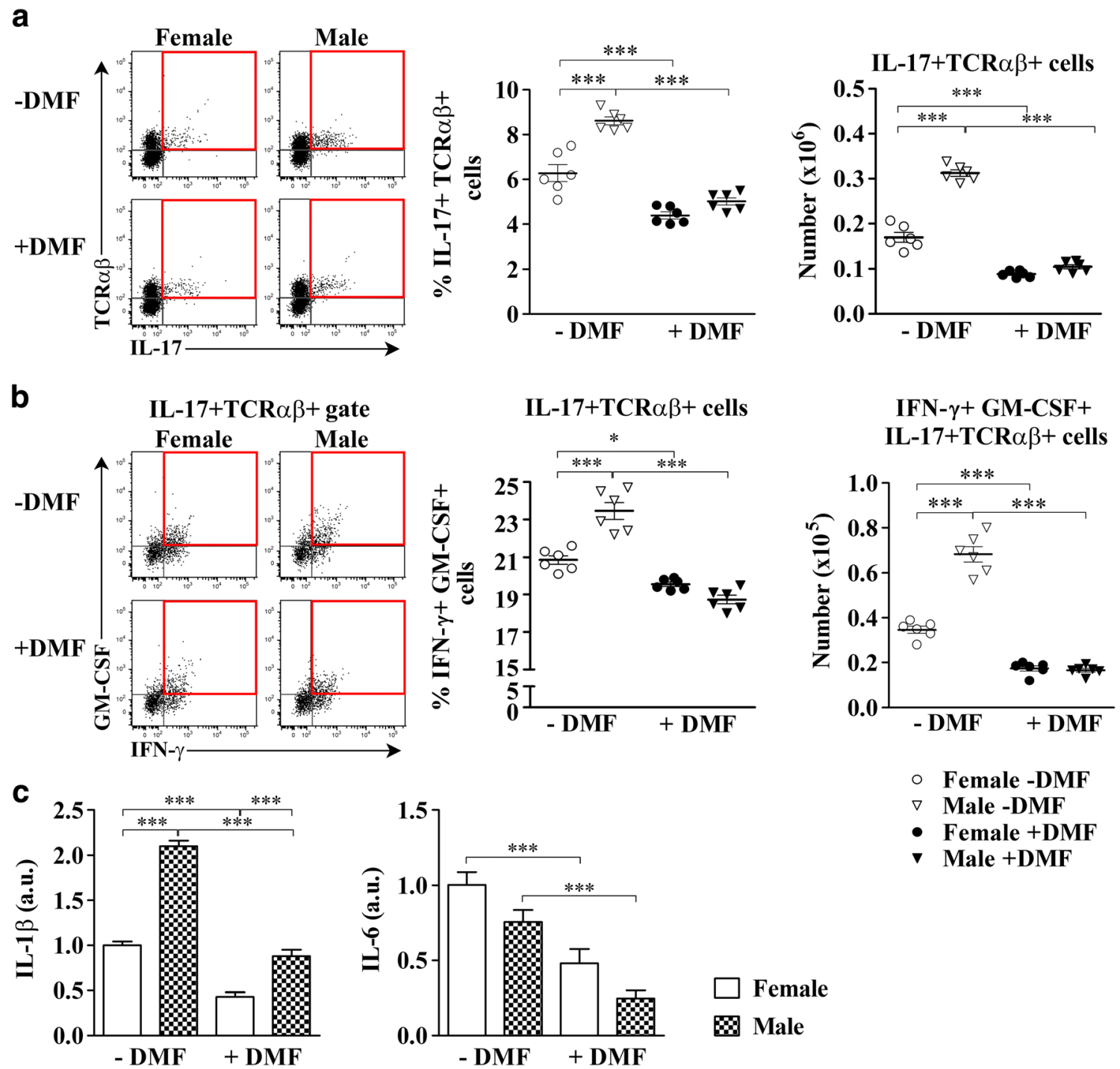

Fig. 3 DMF was more efficient in diminishing the percentage of highly pathogenic multiple-cytokine-producing $\mathrm{T}$ lymphocytes infiltrating spinal cord of male rats immunized for EAE. Flow cytometry dot plots indicate a IL-17 vs TCR $\alpha \beta$ staining of mononuclear cells (MNC) retrieved at the peak of EAE from spinal cord (SC) of female and male rats administered with DMF ( + DMF) or vehicle (-DMF) and b IFN- $\gamma$ vs GM-CSF staining of IL-17+TCR $\alpha \beta+$ lymphocytes gated as shown in a dot plots. Scatter plots indicate a the frequency of IL-17+TCR $\alpha \beta+$ lymphocytes among SC MNC (left) and their number (right) and $\mathbf{b}$ the frequency of IFN- $\gamma+$ GM-CSF+ cells among IL-17+TCR $\alpha \beta+$ lymphocytes (left) and their number (right) in MNC suspensions from $\mathrm{SC}$ of female and male $-\mathrm{DMF}$ and $+\mathrm{DMF}$ rats. $\mathbf{c}$ Bar graphs indicate the

fold change in left IL-1 $\beta$ and right IL-6 mRNA expression in SC tissue from female and male $+\mathrm{DMF}$ rats and male $-\mathrm{DMF}$ rats relative to female -DMF rats, as determined by RT-qPCR at the peak of EAE. Results are normalized to $\beta$-actin expression. Results are from one of two similar experiments each comprising six rats/group. Data are presented as mean \pm S.E.M. Two-way ANOVA showed significant interaction between the effects of treatment and sex for frequency of IL-17+ T cells $\left(F_{(1,20)}=13.40 ; p \leq 0.01\right)$; number of IL-17+ T cells $\left(F_{(1,20)}=82.59\right.$; $p \leq 0.001)$; frequency of IFN- $\gamma+\mathrm{GM}-\mathrm{CSF}+\mathrm{T}$ cells $\left(F_{(1,20)}=20.012\right.$; $p \leq 0.001)$, number of IFN- $\gamma+$ GM-CSF + IL-17+ T cells $\left(F_{(1,20)}=71.03 ; p \leq 0.001\right)$ and IL-1 $\beta$ mRNA expression $\left(F_{(1,20)}=36.79 ; p \leq 0.001\right) . * p \leq 0.05 ; * * * p \leq 0.001$

the expression of IL-6 mRNA was comparable to that measured in females (Fig. 3c). Irrespective of sex, DMF diminished $(p \leq 0.001)$ the expression of IL-1 $\beta$ and IL-6 mRNAs (Fig. 3c). DMF was particularly efficient in reducing IL-1 $\beta$ mRNA expression in males (approx. twofold in females vs approx. threefold in males). The expression of IL- $\beta$ mRNA remained greater $(p \leq 0.001)$ in male than in female +DMF rats, whereas that of IL-6 mRNA was lower in males, but this difference did not reach statistical significance (Fig. 3c).
$D M F$ was more Efficient in Increasing the Frequency of CD163+ Cells among CD11b+CD45+TCR $\alpha \beta-S C$ Mononuclear Cells and Upregulating their CD83 Surface Density in Male Rats Immunized for EAE

Considering (i) bidirectional communication between encephalitogenic CD4+ T lymphocytes and resident-/blood-borne myeloid cells, so that they affect each other's activation and differentiation/polarization [48-50] and (ii) M2 polarizing 
effects of DMF on SC monocytes from experimental models of autoimmune diseases and macrophage cell lines [12, 51], SC microglia/macrophages were investigated for the expression of M2 polarization markers. To identify microglia/macrophages, SC mononuclear cells were subjected to triple CD11b/CD45/ $\operatorname{TCR} \alpha \beta$ immunostaining. They were subjected to the triple instead of CD11b/CD45 double immunostaining as previously suggested [28] because pathogenic $\mathrm{T}$ lymphocytes infiltrating $\mathrm{SC}$ in EAE are also shown to express CD11b [52, 53]. CD11b+ CD45+TCR $\alpha \beta-$ cells were examined for the expression of CD163 molecule, as it is shown to be a marker of microglia and macrophages with anti-inflammatory M2 properties in autoimmune neuroinflammation [54]. More important, in acute rat EAE model CD163+ cells are suggested to be of crucial importance in restricting neuroinflammation, and consequently recovery from paralysis [54]. The frequency of CD163+ cells was similar among CD11b+CD45+TCR $\alpha \beta-$ cells from $\mathrm{SC}$ of male and female - DMF rats (Fig. 4a). DMF elevated $(p \leq 0.001)$ their frequency among CD11b+CD45+TCR $\alpha \beta-$ cells in both sexes, but this effect was more pronounced in males (Fig. 4a). Consequently, the frequency of CD163+ cells was higher $(p \leq 0.001)$ among $\mathrm{CD} 11 \mathrm{~b}+\mathrm{CD} 45+\mathrm{TCR} \alpha \beta-$ cells from SC of male $+\mathrm{DMF}$ rats compared with their female counterparts (Fig. 4a).

Considering that in autoimmune neuroinflammation CD163+ microglia/macrophages are found to be actively phagocyting cells [54], and that apoptotic cell-derived membrane vesicles are shown to induce CD83 upregulation [55], the expression of CD83 on CD11b+CD45+TCR $\alpha \beta-$ cells was also investigated. The frequency of cells expressing surface CD83 was similar among $\mathrm{CD} 11 \mathrm{~b}+\mathrm{CD} 45+\mathrm{TCR} \alpha \beta-\mathrm{SC}$ cells from male and female - DMF rats (Fig. 4b). DMF induced a similar sex-specific pattern of changes in the frequency of CD83+ cells among $\mathrm{CD} 11 \mathrm{~b}+\mathrm{CD} 45+\mathrm{TCR} \alpha \beta-\mathrm{SC}$ cells to that observed in the frequency of CD163+ cells. Namely, their frequency increased $(p \leq 0.001)$ in female (approx. threefold) and male (approx. fivefold $)+$ DMF rats of both sexes, so it was higher $(p \leq 0.001)$ in male + DMF rats (Fig. 4b). Judging by CD83 MFI, DMF also upregulated the surface density of CD83 on CD83+CD11b+ CD45+TCR $\alpha \beta-$ cells from rats of both sexes. Consequently, CD83 surface density was also higher $(p \leq 0.001)$ on CD83+ $\mathrm{CD} 11 \mathrm{~b}+\mathrm{CD} 45+\mathrm{TCR} \alpha \beta-$ cells from male rats (Fig. $4 \mathrm{~b}$ ).

Being aware that markers of anti-inflammatory myeloid cells depend on the disease model and the organ from which they are isolated [56], we also examined (i) the expression of arginase-1 (Arg-1), the enzyme catalyzing the hydrolysis of Larginine to ornithine and urea, in SC and (ii) the production of urea in overnight SC mononuclear cell cultures. We decided for Arg-1 as it is suggested to be the best characterized marker of the anti-inflammatory macrophages/microglia in the CNS [57, 58], and, particularly, in acute rat EAE model [59]. The amount of Arg-1 mRNA in SC from female and male -DMF rats did not significantly differ (Fig. 5a). Consistent with the frequency of CD163+ cells, DMF upregulated the expression of Arg-1 mRNA in SC from both female $(p \leq 0.05)$ and male $(p \leq 0.001)$ rats, but DMF was more efficient in this respect in males (Fig. 5a). The analysis of urea concentration in SC mononuclear cell cultures showed comparable concentration of urea in the cultures from female and male -DMF rats (Fig. 5a). However, compared with SC mononuclear cell cultures from - DMF rats, in those from + DMF rats the concentration of urea was elevated ( $p \leq 0.05$ in female and $p \leq 0.001$ male cultures, respectively), and this effect of DMF was higher $(p \leq 0.001)$ in male rat cultures (Fig. 5a).

Considering that, in general, mutually exclusive expression of inducible nitric oxide synthase (iNOS, catalyzes the production of NO from arginine) and Arg-1 in individual macrophages prevails [60], the expression of iNOS mRNA in SC tissue and the production of $\mathrm{NO}$ in overnight SC mononuclear cell cultures were also examined. The expression of iNOS mRNA in SC tissue did not statistically significantly differ between female and male $-\mathrm{DMF}$ rats (Fig. 5b). Irrespective of sex, DMF diminished $(p \leq 0.05)$ iNOS mRNA expression in SC tissue, so that comparable amounts of this mRNA were found in female and male SC tissue (Fig. 5b). The analysis of NO production by SC mononuclear cell cultures showed higher $(p \leq 0.05) \mathrm{NO}$ concentration in the cultures from male compared with female-DMF rats (Fig. 5b). We failed to show statistically significant difference in NO concentration between SC mononuclear cell cultures from $-\mathrm{DMF}$ and $+\mathrm{DMF}$ female rats (Fig. 5b). In the presence of DMF, NO concentration diminished in SC mononuclear cell cultures from rats of both sexes, but this decrease reached statistical significance $(p \leq 0.01)$ only in those from male rats (Fig. 5b).

Finally, considering that DMF is shown to favor monocyte/ macrophage polarization, at least partly, through mobilization of anti-inflammatory $\mathrm{Nrf} 2 / \mathrm{HO}-1$ axis and upregulation of $\mathrm{HO}$ 1 level $[12,51]$, the expression of Nrf2 and HO-1 mRNAs in $\mathrm{SC}$ tissue was examined. There were no significant differences in the expression of mRNAs for Nrf2 and HO-1 in SC from male compared with female -DMF rats (Fig. 5c). Irrespective of sex, DMF augmented $(p \leq 0.001)$ the expression of $\mathrm{Nrf} 2$ and HO-1 mRNAs in SC (Fig. 5c). These effects of DMF were more prominent in males, leading to greater $(p \leq 0.001) \mathrm{SC}$ expression of both Nrf2 and HO-1 mRNAs in male compared with female + DMF rats (Fig. 5c).

\section{Sexual Dimorphism in DMF Influence on Redox Status in SC Tissue and Blood from Male Rats Immunized for $\mathbf{E A E}$}

DMF was more Efficient in Reducing Oxidative Tissue Damage in SC Tissue of Male Rats

In the second step, considering the previous finding indicating sexually dimorphic effects of DMF on neuroinflammation, 


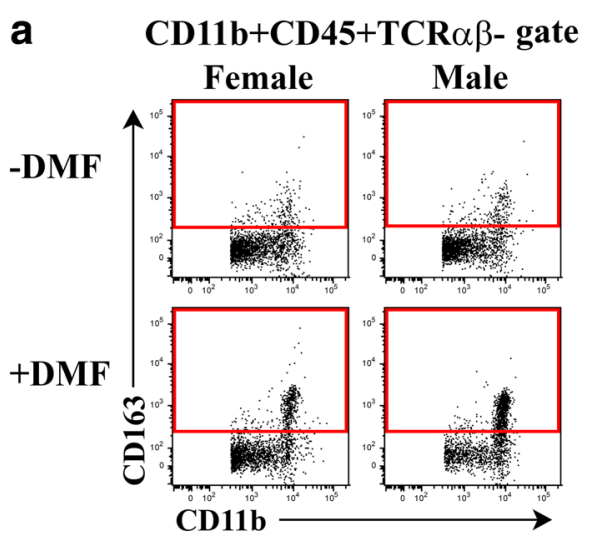

CD11b + CD45+TCR $\alpha \beta-$ cells

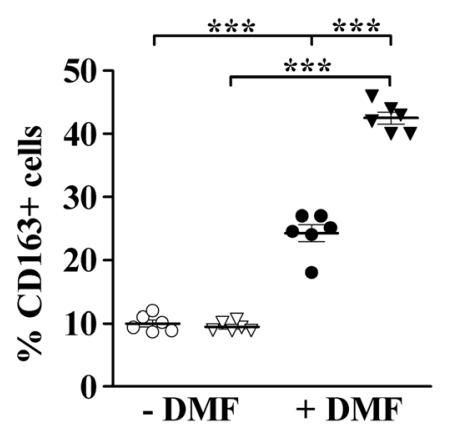

b $\quad$ CD11b + CD45+TCR $\alpha \beta$ - gate

CD11b+CD45+TCR $\alpha \beta-$ cells
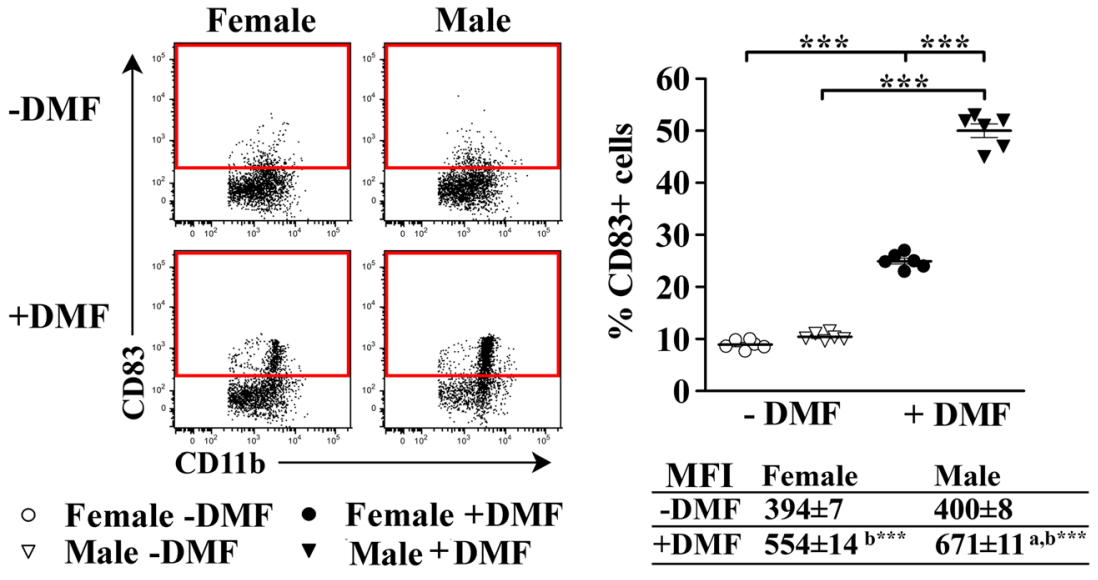

Fig. 4 DMF was more efficient in increasing the frequency of CD163+ cells among $\mathrm{CD} 11 \mathrm{~b}+\mathrm{CD} 45+\mathrm{TCR} \alpha \beta-$ cells and their expression of CD83 in spinal cord of male than female rats. Flow cytometry dot plots show a CD163 and $\mathbf{b}$ CD83 staining of CD11b+CD45+TCR $\alpha \beta-$ cells retrieved at the peak of EAE from spinal cord (SC) of female and male rats administered with DMF (+DMF) or vehicle (-DMF). Gating strategy for CD11b+CD45+TCR $\alpha \beta-$ cells is shown in Supplementary Fig. 2. Scatter plots indicate the frequency of a CD163+ and $\mathbf{b}$ CD83+ cells among $\mathrm{CD} 11 \mathrm{~b}+\mathrm{CD} 45+\mathrm{TCR} \alpha \beta-\mathrm{SC}$ cells. b Numbers in the table

represent $\mathrm{CD} 83$ mean fluorescence intensity (MFI) on CD83+CD11b+ $\mathrm{CD} 45+\mathrm{TCR} \alpha \beta-$ cells retrieved from SC of female and male $-\mathrm{DMF}$ and + DMF rats. Results are from one of two similar experiments each comprising six rats/group. Data are presented as mean \pm S.E.M. Twoway ANOVA showed significant interaction between the effects of treatment and sex for the frequency of CD163+ $\left(F_{(1,20)}=44.85 ; p \leq 0.001\right)$ and $\mathrm{CD} 83+\left(F_{(1,20)}=244.7 ; p \leq 0.001\right)$ cells and CD83 MFI $\left(F_{(1,20)}=30.09 ; p \leq 0.001\right) . * * * p \leq 0.001 ;{ }^{\mathrm{a}}$ Male vs female; ${ }^{\mathrm{b}}+\mathrm{DMF}$ vs sex-matched -DMF

and data indicating that RNS and ROS represent the major mediators in the inflammation-induced neuronal tissue damage in MS and EAE [8], apart from SC cell capacity to produce $\mathrm{NO}$, the generation of $\mathrm{O}_{2}{ }^{-}$in $\mathrm{SC}$ tissue was investigated. Indeed, the level of $\mathrm{O}_{2}{ }^{-}$, a central pro-oxidant generated in several enzymatic and non-enzymatic reactions, was also greater $(p \leq 0.05)$ in $\mathrm{SC}$ of male -DMF rats exhibiting more severe disease than in their female counterparts (Fig. 6a). DMF diminished $(p \leq 0.05$ and $p \leq 0.001$ in female and male rats, respectively) $\mathrm{SC}$ level of $\mathrm{O}_{2}{ }^{-}{ }^{-}$in rats of both sexes, but it was more efficient in this respect in males (Fig. 6a). Consequently, the level of $\mathrm{O}_{2}{ }^{-}$- was comparable in SC of female and male +DMF rats (Fig. 6a).

In accordance with the previous findings, TOC, reflecting the overall pro-oxidant tissue potential, and consequently assumed to be a comprehensive marker of the total tissue oxidative stress burden, was greater in $\mathrm{SC}$ of male -DMF rats compared with female rats, but this difference did not reach statistical significance (Fig. 6a). DMF decreased TOC in SC from both male and female rats, but this decrease reached statistical significance $(p \leq 0.01)$ only in males (Fig. 6a). Thus, TOC was similar in SC of female and male +DMF rats (Fig. 6a).

To elucidate mechanism standing behind the previously described phenomenon, the activity of $\mathrm{XO}$, which is shown to be the main enzyme catalyzing $\mathrm{O}_{2}{ }^{-}$- generation in inflammatory settings [61], was examined. Its activity was greater $(p \leq 0.001)$ in male than in female -DMF rat SC (Fig. 6a). DMF reduced $(p \leq 0.001) \mathrm{XO}$ activity in $\mathrm{SC}$ of rats of both sexes, abrogating sexual dimorphism observed in -DMF rats (Fig. 6a).

Based on data indicating that the imbalance between prooxidants and anti-oxidants in favor of the former leads to cell damage, some important anti-oxidant mechanisms were also 
Fig. 5 Sex-based differences in DMF effects on the expression of arginase-1, Nrf2 and heme oxigenase 1 in the spinal cord tissue of rats immunized for EAE. Bar graphs indicate the fold change in a arginase-1 (Arg-1); b iNOS; c nuclear factor, erythroid 2-like 2 (Nrf2) and heme oxigenase 1 (HO-1) mRNA expression in spinal cord (SC) tissue from female and male + DMF rats and male - DMF rats relative to female $-\mathrm{DMF}$ rats, as determined by RT-qPCR at the peak of EAE. Results are normalized to $\beta$-actin expression. Inserted bar graphs indicate concentration of $\mathbf{a}$ urea and $\mathbf{b} \mathrm{NO}$ in overnight mononuclear SC cell cultures from female and male - DMF and + DMF rats. Results are from one of two similar experiments each comprising six rats/group. Data are presented as mean \pm S.E.M. Two-way ANOVA showed significant interaction between the effects of treatment and sex for Arg-1

$\left(F_{(1,20)}=16.09 ; p \leq 0.001\right), \mathrm{Nrf} 2$ $\left(F_{(1,20)}=5.926 ; p \leq 0.001\right)$, and HO-1 mRNA expression $\left(F_{(1,20)}=23.58 ; p \leq 0.001\right)$, and for urea concentration $\left(F_{(1,20)}=9.148 ; p \leq 0.01\right)$. $* p \leq 0.05 ; * * p \leq 0.01$; $* * * p \leq 0.001$
Spinal cord tissue
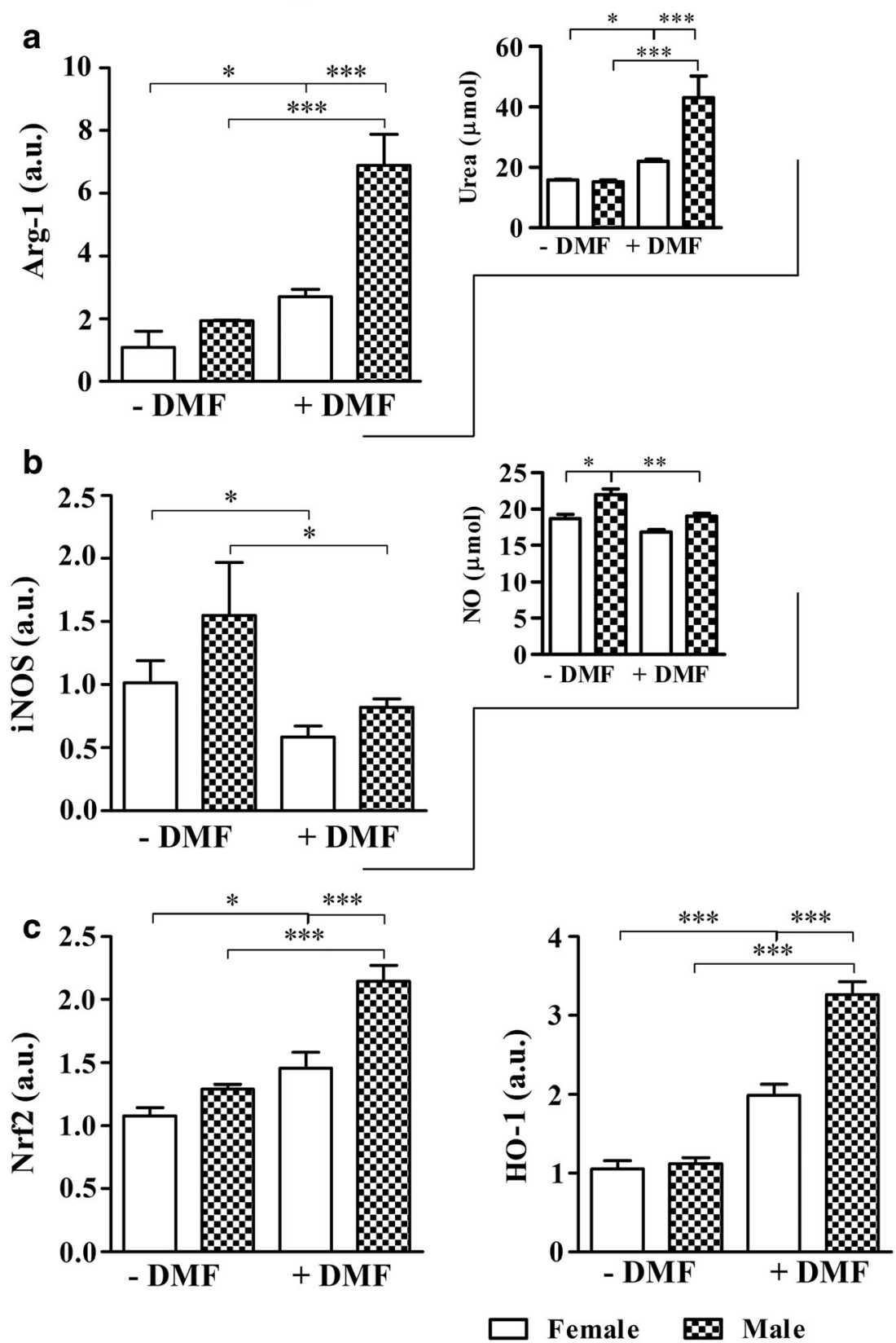

examined. Given that SOD: (i) represents the major antioxidant defense systems against $\mathrm{O}_{2}{ }^{-}$and (ii) plays the critical role in the inhibition of $\mathrm{NO}$ oxidative inactivation and thereby peroxynitrite $\left(\mathrm{ONOO}^{-}\right)$formation and endothelial and mitochondrial dysfunction [62], its activity in $\mathrm{SC}$ was examined. The higher level of $\mathrm{O}_{2}{ }^{-}$, and most likely greater generation of $\mathrm{NO}$ in $\mathrm{SC}$ of male compared with female -DMF rats, were accompanied by lower $(p \leq 0.01)$ SOD activity (Fig. 6b). DMF enhanced SOD activity in female $(p \leq 0.05)$ and male $(p \leq 0.001)$ rat SC (Fig. 6b). Additionally, it led to the loss of sexual dimorphism in SOD activity in rat SC (Fig. 6b).
Next, considering important role of GSH-dependent antioxidant enzyme system in cellular protection against ROS, and particularly influence of DMF on GSH cellular levels [63], its levels in SC were also investigated. We failed to show any significant sex difference in GSH level in SC of -DMF rats (Fig. 6b). However, irrespective of sex, DMF increased $(p \leq 0.001)$ GSH level in SC, and the magnitude of this effect did not significantly differ between sexes (Fig. 6b).

Furthermore, SC from all animals was examined for TAC as a comprehensive measure of the total anti-oxidant potential. As expected from the previous analyses, TAC was lower $(p \leq 0.05)$ in male than in female - DMF rat SC (Fig. 6b). In 
Fig. 6 DMF affected redox status in the spinal cord tissue from rats of both sexes in a sexually dimorphic manner. Scatter plots show a pro-oxidant parameters: $\mathrm{O}_{2}{ }^{\cdot-}$ level, total pro-oxidant capacity (TOC), and xanthine oxidase (XO) activity. b Antioxidant parameters: superoxide dismutase (SOD) activity, glutathione (GSH) level and total anti-oxidant capacity (TAC), and c Parameters of tissue damage: malondialdehyde (MDA) and advanced oxidation protein products (AOPP) levels, at the peak of EAE in the spinal cord tissue of female and male rats administered with DMF (+DMF) or vehicle $(-\mathrm{DMF})$. Results are from one of two similar experiments each comprising six rats/group. Data are presented as mean \pm S.E.M. Two-way ANOVA showed significant interaction between the effects of treatment and sex for $\mathrm{O}_{2}{ }^{\circ}$

$\left(F_{(1,20)}=5.397 ; p \leq 0.05\right), \mathrm{XO}$

$\left(F_{(1,20)}=38.35 ; p \leq 0.001\right), \mathrm{SOD}$

$\left(F_{(1,20)}=55.12 ; p \leq 0.001\right), \mathrm{TAC}$

$\left(F_{(1,20)}=4.885 ; p \leq 0.05\right)$, and

$\operatorname{AOPP}\left(F_{(1,20)}=12.53 ; p \leq 0.01\right)$.

$* p \leq 0.05 ; * * p \leq 0.01$

$* * * p \leq 0.001$
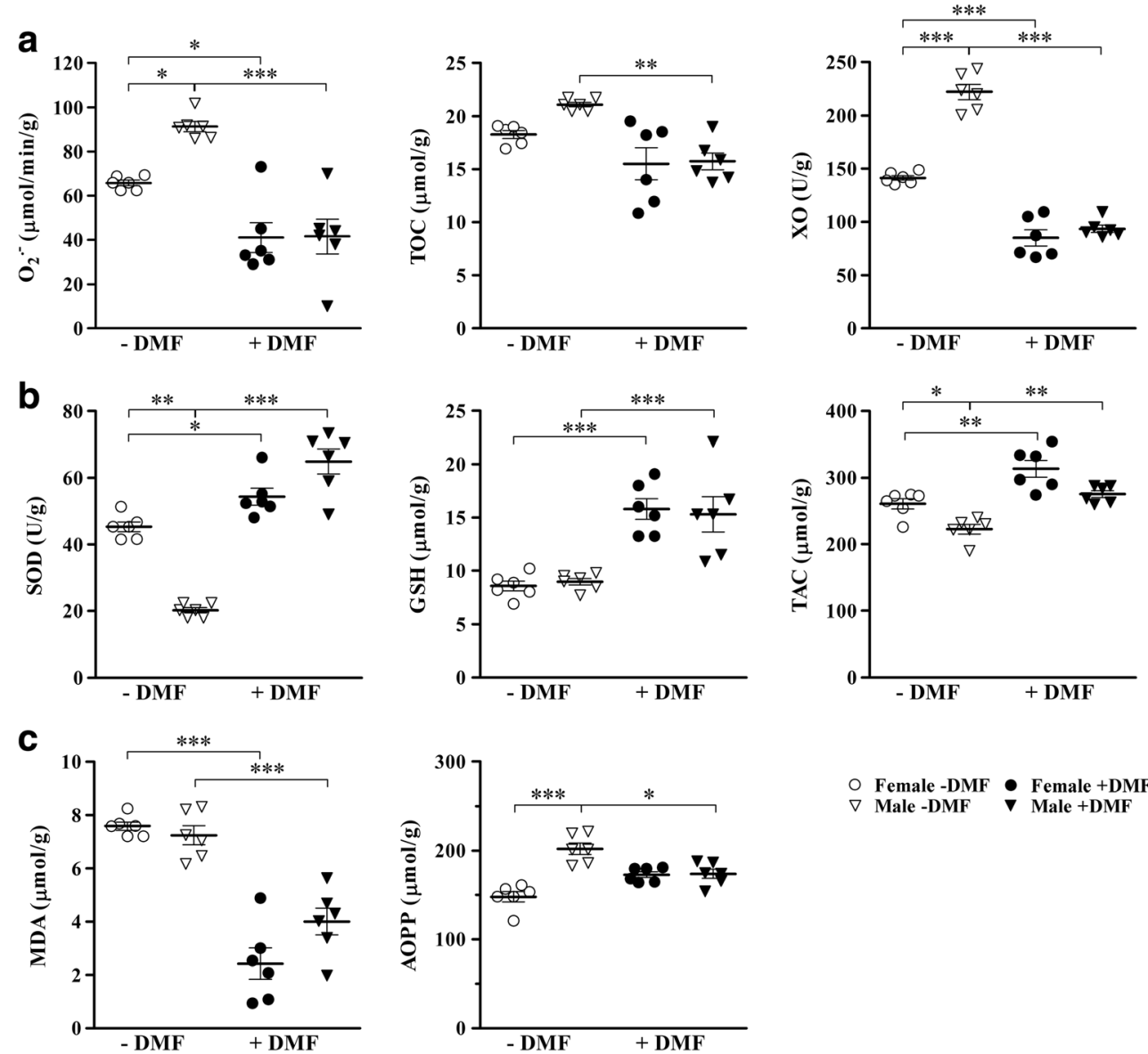

O Female -DMF $\bullet$ Female +DM $\nabla$ Male -DMF $\checkmark$ Male +DMF
$\mathrm{SC}$ of $+\mathrm{DMF}$ rats of both sexes $(p \leq 0.01)$, TAC levels were higher than in sex-matched -DMF rats (Fig. 6b). Besides, TAC level was similar in $\mathrm{SC}$ of female and male +DMF rats (Fig. 6b).

Finally, the parameters of SC oxidative damage, i.e., levels of MDA, a marker of lipid oxidative degradation, and AOPP, a marker of oxidative protein damage, were explored. Despite more severe clinical EAE in male -DMF rats, MDA level in their SC did not significantly differ from that in their female counterparts (Fig. 6c). DMF diminished $(p \leq 0.001)$ MDA level in SC of both female and male rats (Fig. 6c). The magnitude of this effect did not significantly differ between sexes (Fig. 6c).

On the other hand, AOPP level was higher $(p \leq 0.001)$ in $\mathrm{SC}$ of male compared with female $-\mathrm{DMF}$ rats (Fig. 6c). DMF diminished $(p \leq 0.05)$ AOPP level only in SC of male rats, so it did not significantly differ in $\mathrm{SC}$ of female and male +DMF rats (Fig. 6c).

\section{Sexually Dimorphic Effects of DMF on Redox Status in Blood of Rats Immunized for EAE}

Considering data from our previous study indicating multiple correlations between $\mathrm{SC}$ and peripheral blood oxidative status parameters [7], the redox status was also assessed in circulation of rats subjected to DMF treatment. There were no significant differences in the plasma level of either $\mathrm{O}_{2}{ }^{-}$ or TOC across experimental groups (Fig. 7a).

However, SOD activity was lower $(p \leq 0.01)$ in the plasma of male -DMF rats when compared with their female counterparts (Fig. 7b). DMF increased $(p \leq 0.001)$ its activity in rats of both sexes, leading to the loss of sexual dimorphism (Fig. 7b). Next, influence of sex and DMF on plasma TAC was addressed. In agreement with SOD activity, sexual dimorphism was also found in the value of TAC, so it was lower $(p \leq 0.001)$ in male compared with female -DMF rats (Fig. 7b). DMF-induced changes in plasma TAC exhibited the similar pattern to those observed in plasma SOD activity. Specifically, the value of this parameter increased in plasma of + DMF rats $(p \leq 0.01$ and $p \leq 0.001$ in female and male rats, respectively) (Fig. 7b). Besides, DMF led to the loss of sexual dimorphism in the TAC value (Fig. 7b).

Next, PAB was analyzed. There was no significant sex difference in the value of this parameter in $-\mathrm{DMF}$ rats (Fig. 7c). However, DMF decreased $(p \leq 0.001)$ its value in rats of both sexes to a similar extent (Fig. 7c). Consequently, there was no significant sex differences in PAB in +DMF rats (Fig. 7c).

Finally, the influence of DMF on plasma MDA and AOPP levels was examined. Neither sex nor DMF influenced plasma 
Fig. 7 DMF affected redox status in the blood from rats of both sexes immunized for EAE. Scatter plots show a pro-oxidant parameters: $\mathrm{O}_{2}{ }^{-}{ }^{-}$level and total pro-oxidant capacity (TOC), b Anti-oxidant parameters: superoxide dismutase (SOD) activity and total anti-oxidant capacity (TAC), c Prooxidant-anti-oxidant balance (PAB) and $\mathbf{d}$ Parameters of tissue damage: malondialdehyde (MDA) and advanced oxidation protein products (AOPP) levels, at the peak of EAE in the plasma of female and male rats administered with DMF (+DMF) or vehicle (-DMF). Results are from one of two similar experiments each comprising six rats/group. Data are presented as mean \pm S.E.M. Two-way ANOVA showed significant interaction between the effects of treatment and sex for SOD

$\left(F_{(1,20)}=7.257 ; p \leq 0.05\right)$, TAC

$\left(F_{(1,20)}=6.183 ; p \leq 0.05\right), \mathrm{PAB}$

$\left(F_{(1,20)}=7.929 ; p \leq 0.05\right)$, and $\operatorname{AOPP}\left(F_{(1,20)}=5.039 ; p \leq 0.05\right)$. $* p \leq 0.05 ; * * p \leq 0.01$;

$* * * p \leq 0.001$ a
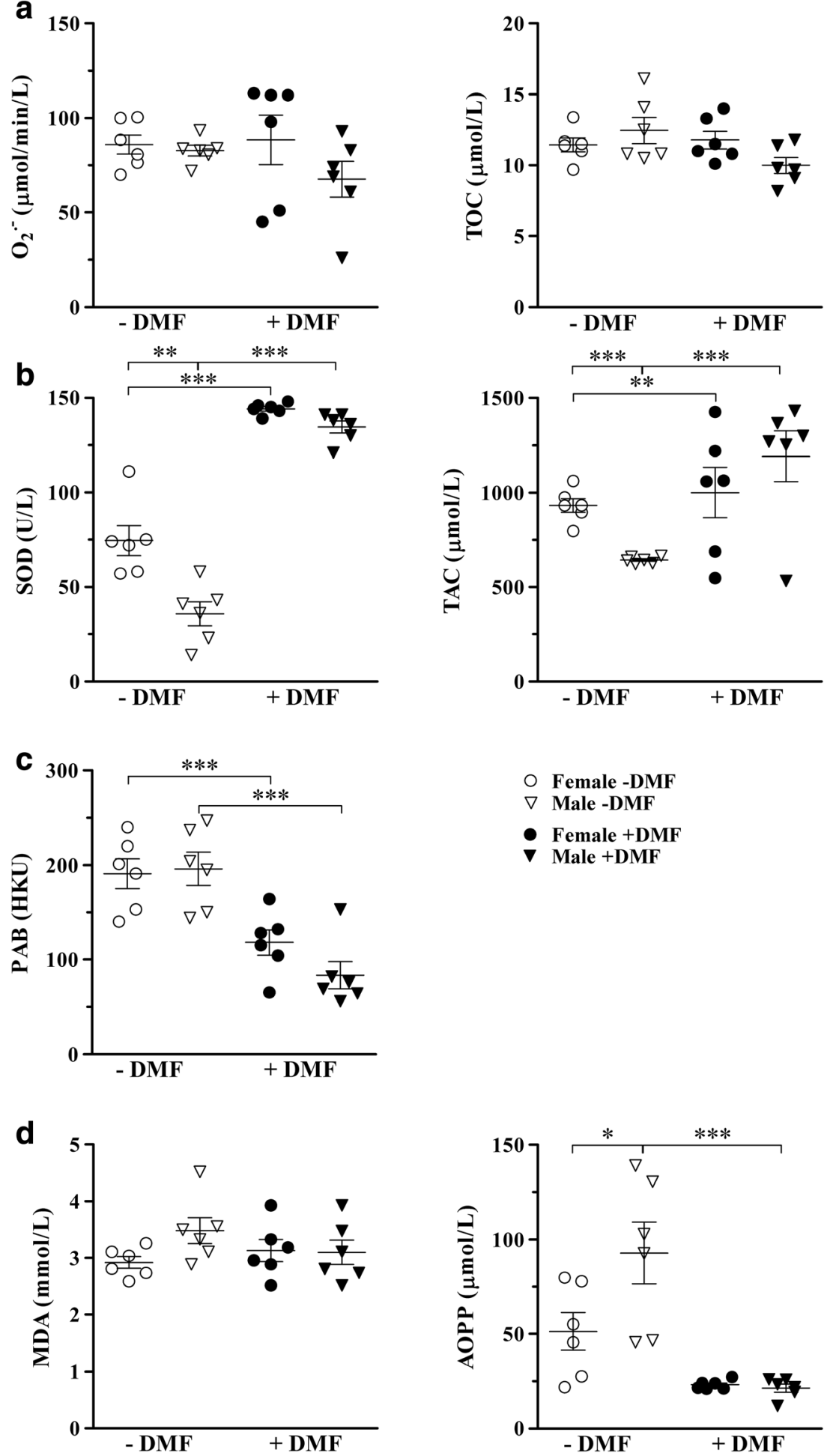

O Female -DMF

$\nabla$ Male -DMF

- Female +DMF

$\checkmark$ Male +DMF
MDA level (Fig. 7d). Plasma AOPP level was higher $(p \leq 0.05)$ in male than in female -DMF rats (Fig. 7d). DMF influenced $(p \leq 0.001)$ AOPP level only in male rats, leading to a profound decrease (Fig. 7d). Consequently, its value was comparable in female and male +DMF rats (Fig. 7d).

\section{Discussion}

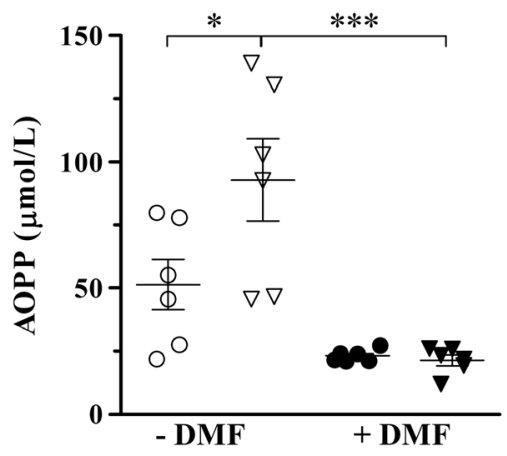

The study showed that DMF administration from the day of immunization influences EAE development in a sex-specific manner. Consistently, DMF attenuated the severity of EAE in 
rats of both sexes, but this effect was more prominent in males, leading to the loss of the sexual dimorphism observed in control-DMF rats. This sexual diergism cannot be ascribed to sex differences in either metabolism or pharmacokinetic profile of DMF (European Medicines Agency 26 November 2013 EMA/800904/2013 Corr. 1 Committee for Medicinal Products for Human Use (CHMP) Assessment report: Tecfidera, http://www.ema.europa.eu/ema/index.jsp?curl= pages/medicines/human/medicines/002601/human_med 001657.jsp\&mid=WC0b01ac058001d124). Thus, it may be assumed that this phenomenon reflected sex differences in the sensitivity of DMF targets. DMF is shown to exert beneficial effects on EAE by affecting multiple cellular and molecular targets $[9,12,64,65]$, so its influence on distinct targets was systematically examined.

\section{DMF Exerted more Pronounced Immunomodulatory/Anti-inflammatory Effects in Male Rats}

In accordance with the previous studies $[64,65]$, we retrieved fewer mononuclear cells, and CD4+ T lymphocytes among them, from + DMF rats compared with sex-matched $-D M F$ animals, and revealed that the magnitude of this DMF effect was greater in males, leading to the loss of sexual dimorphism observed in controls. Although DMF is shown to induces apoptosis in purified human T lymphocytes [43], we failed to show any significant changes in the frequency of Annexin $\mathrm{V}+$ cells among CD4+ T lymphocytes from either female or male SC. Given that the frequency of apoptotic cells among T cells from fresh SC mononuclear cell suspensions, differently from that among purified $\mathrm{T}$ lymphocytes in culture, reflects not only proapototic DMF action, but also efficacy of phagocytic cell to eliminate apoptotic cells, this apparent discrepancy could be reconciled by our findings indicating that: (i) the DMF-induced increase in the frequency of phagocyting antiinflammatory CD163+ cells within CD11b+CD $45+\mathrm{TCR} \alpha \beta-$ myeloid cells, and (ii) this increase was more prominent in males. Several findings strongly corroborate the notion indicating that DMF augments the elimination of apoptotic cells by increasing the frequency of phagocyting CD163+ cells. Firstly, it is shown that CD163+ microglial cells/ macrophages accumulating in acute active MS lesions are myelin basic protein positive, i.e., the cells that ingested tissue debris [54]. Secondly, in vitro incubation of LPS-stimulated macrophage cell line RAW264.7 with myelin turned these cells from inflammatory into phagocyting cells exhibiting CD163+ anti-inflammatory phenotype [54]. Furthermore, DMF induced changes in the frequency of cells bearing CD83, the molecule strongly upregulated in phagocyting cells by apoptotic cell-derived membrane vesicles [55] and its surface density on these cells showed the same pattern as that in CD163+ cell frequency. Moreover, given that CD163+ myeloid cells, which are shown to be crucial in restricting neuroinflammation in acute EAE model, express Arg-1 [59], the augmented Arg-1 expression in SC from +DMF rats, being particularly pronounced in males, is also fully consistent with the DMF-induced alterations in the frequency of CD163+ myeloid cells. The opposite influence of DMF on the SC expression of Arg-1 and iNOS supports the previous findings [60]. The additional support for the herein reported DMF-induced alterations in the frequency of CD163+ myeloid cells comes from our findings showing that DMF upregulated the expression of $\mathrm{Nrf} 2$ and $\mathrm{HO}-1$, in a sex-specific way. Namely, it has been recently shown that: (i) DMF exerts favorable clinical effects in rat experimental autoimmune neuritis model and mouse acute EAE model by increasing the number of anti-inflammatory macrophages in the spleen and sciatic nerves, respectively $[12,51]$ and (ii) these DMF effects are, at least partly, related to the mobilization of antiinflammatory Nrf2/HO-1 axis and upregulation of HO- 1 level $[12,51]$. To corroborate sex differences in the magnitude of DMF effects on Nrf2/HO-1 axis are data showing sex differences in basal and induced $\mathrm{Nrf} / \mathrm{HO}-1$ pathway activity and HO-1 levels in neural and extraneural tissues [66-68]. Additionally, it should be pointed out that the diminished infiltration of SC with CD4+ T lymphocytes in the response to DMF could be ascribed to their impaired migration [65, 69-71], reflecting inhibitory effect of DMF on NF-KBdependent transcription of genes encoding chemokines and adhesion molecules $[14,15]$. In this context, sexual dimorphism in DMF influence on the number of CD4+ T lymphocytes infiltrating SC may be related to (i) sex-based differences in basal and stimulated NF- $\mathrm{kB}$ expression and activity $[72,73]$ and (ii) herein reported sex-specific influence of DMF on Nrf2 expression, as DMF-induced Nrf2 signaling pathway activity leads to inhibition of NF-kB activation $[9,17,18$, 74] and vice versa. Finally, considering that the diminished CD134 surface density on CD4+ T lymphocytes limits their clonal expansion and survival [75], sexspecific (i.e., particularly pronounced in males) decrease in the CD134 surface density on CD134+CD4+ T lymphocytes is also consistent with our assumption that DMF-induced sex-specific changes in the frequency of phagocyting CD163+ cells mask its proapoptotic effect on CD4+ T lymphocytes. The sex-specific DMF-induced effect on CD4+ $\mathrm{T}$ lymphocyte reactivation (substantiated in more prominent the decrease in not only CD134 surface expression, but also in the frequency CD134+ lymphocytes in males) is consistent with data indicating that in vitro DMF diminishes antigen-specific proliferation of splenocytes obtained from a rat model of experimental autoimmune neuritis [51]. The sex-specific diminishing effect of DMF on CD4+ T lymphocyte proliferation could be linked with the sexually dimorphic DMF upregulation of CD83 surface density on myeloid CD11b+CD45+ 
TCR $\alpha \beta-$ cells, as CD83 is suggested to play an important inhibitory role during interactions between antigen presenting and T cells [76-79]. More specifically, CD83 released from activated non-lymphoid cells (through shedding of cell surface-associated CD83), and in the soluble form, strongly down modulates the antigen presenting cell-mediated $\mathrm{T}$ lymphocyte stimulation [77-79]. To add an extra weight to our assumption is the study describing effects of the treatment with soluble CD83 on neuroinflammation in a murine EAE model (also CD4+ $\mathrm{T}$ cellmediated disease model for the early inflammatory stage of MS) [80]. The study showed that the administration of soluble CD83 during the initial phase of EAE (the immunological onset of the disease), or at a later period, which spans the onset of the first clinical symptoms, clearly reduced the paralysis [80]. In the same line are recently obtained data indicating that highly upregulated CD83 expression on dendritic cell surface, through CD83 homotypic interactions, leads to downregulation of inflammation and promotion of mucosal homeostasis in an experimental colitis model [81].

Apart from diminishing the number of CD4+ T lymphocytes infiltrating $\mathrm{SC}$, in agreement with the findings from mouse EAE model and MS [12, 82], DMF reduced the number of IL-17+ T lymphocytes infiltrating SC, and the frequency of IFN- $\gamma+$ GM-CSF+ cells, which are shown to comprise highly pathogenic in EAE models. These effects of DMF were also more prominent in males, leading to the loss of the sexual dimorphism observed in controls. To support the latter finding was the more pronounced DMF-related decrease in the frequency of CD11b-expressing (CD11b+) T lymphocytes in males (Supplementary Fig. 1). In EAE animals, CD11b+ T cells isolated from SC are suggested to correspond to pathogenic GM-CSF-producing T lymphocytes [53]. The previous findings could be, at least partly, related to the sex-specific DMF-induced changes in the SC myeloid cell M2 polarization, and consequent changes in the expression of cytokines (IL-1 $\beta$ and IL-6) driving differentiation of highly pathogenic IL-17+ T lymphocytes [12, 82].

\section{DMF was Efficiently Reduced Oxidative Stress in Male Rats Immunized for EAE}

In accordance with the sexually dimorphic immunoregulatory/ anti-inflammatory effects of DMF observed at lymphocyte and myeloid cell population level, sexually dimorphic magnitude of the decrease in $\mathrm{SC}$ levels of both $\mathrm{NO}$ and $\mathrm{O}_{2}{ }^{-}$- was found in $+\mathrm{DMF}$ rats compared with controls. However, considering that (i) NF- $\mathrm{KB}$-targeted genes play a major role in the regulation of ROS and RNS generation at the level of single cell $[83,84]$ and (ii) DMF inhibits NF-kB-dependent gene transcription [14, 15], in a sexually dimorphic manner [72, 73], it may be assumed that the effects of DMF on the generation of damaging pro- oxidants also reflected DMF-induced changes at the singlecell level. Additionally, DMF enhanced the activity of cell defense mechanisms, in a sex-specific manner. Namely, it enhanced SOD activity in rats of both sexes, but to a greater extent in males, abrogating the sexual dimorphism registered in $-\mathrm{DMF}$ rats. This most likely reflected sexually dimorphic influence on Nrf2 expression [85]. Furthermore, in accordance with findings indicating that prolonged DMF treatment leads to upregulation of anti-oxidant responses, including GSH response [63], we found elevated GSH levels in $\mathrm{SC}$ of $+\mathrm{DMF}$ rats compared with sex-matched -DMF once. However, differently from SOD response, this response was not sexually dimorphic. The data indicating that fumaric acid esters may modulate cellular GSH through Nrf2-independent mechanisms [86], may offer a plausible explanation for the previous findings. The diminished pro-oxidant generation in SC accompanied by enhanced neuroprotective mechanisms in response to DMF led to diminished MDA in + DMF rats of both sexes and AOPP levels in male + DMF rats in respect to their-DMF counterparts. This is consistent with data indicating sexual dimorphism in mechanisms playing protective/ reparatory role in SC tissue damage [87].

Finally, consistent with our previous study [7], the changes in SC redox status registered in $+\mathrm{DMF}$ rats were followed by alterations in the parameters of plasma redox status. It has been previously shown that plasma AOPP level may be used as a simple plasma marker to assess EAE activity, predict the severity of disease course, and perhaps response to therapy [7]. Indeed, in male rats, DMF diminished plasma AOPP level and abolished sexual dimorphism observed in -DMF rats characterized by the greater AOPP value in males exhibiting more severe neurologic deficit. Additionally, a high correlation $(0.762 ; p \leq 0.001)$ between MDA levels in SC and plasma PAB levels was observed. This is also consistent with our previous study showing that PAB may be used as a parameter indicating the degree of SC oxidative damage [7].

\section{Conclusions}

DMF significantly attenuated EAE severity in rats of both sexes, leading to loss of the sexual dimorphism observed in control animals. The sex-specific influence of DMF on clinical EAE underpinned sex-based differences in DMF efficacy to induce anti-inflammatory phagocyting myeloid cells with, most likely, high expression of regulatory CD83 molecule (Fig. 8). This phenomenon most likely contributed the heightened sensitivity of genes encoding $\mathrm{Nrf} 2 / \mathrm{HO}-1$ expression to DMF in males. To support this notion are data indicating (i) sex bias in basal and stimulated Nrf2 expression in neural and non-neural tissues [66-68] and (ii) sex differences in the responsiveness of some other genes to induction by different, including anti-oxidant, agents [88, 89]. Consistent with the 


\section{Dimethyl fumarate}

(more prominent effects in males)

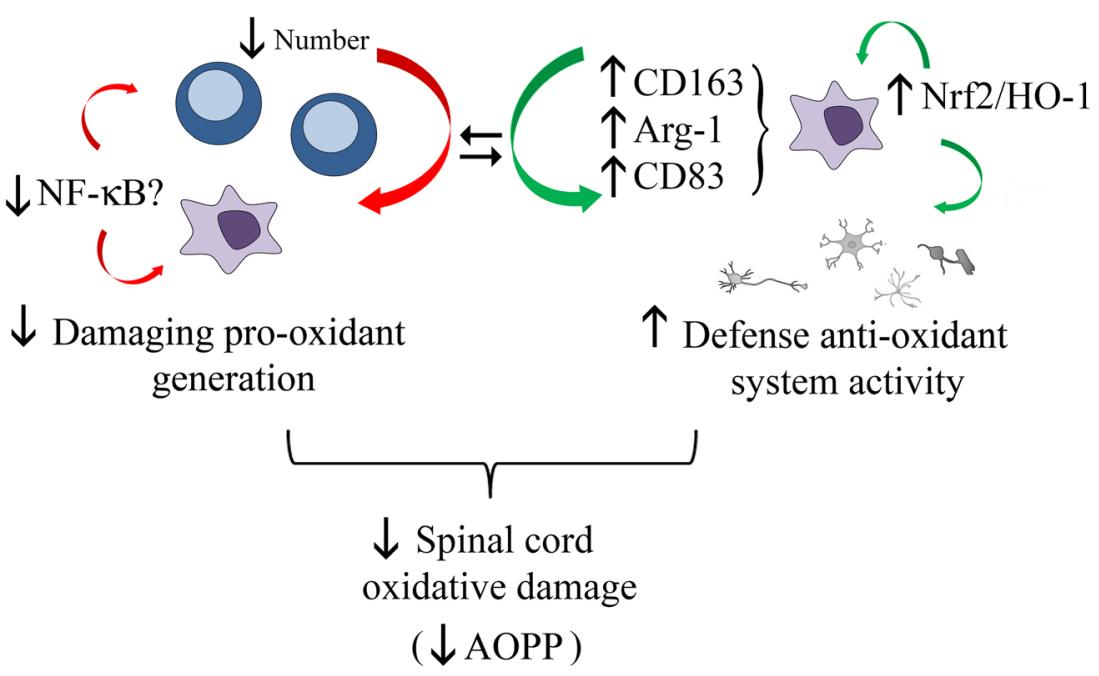

$($ IFN- $\gamma+$ GM-CSF+)IL-17+ T lymphocytes $\downarrow$ Decreased $\uparrow$ Increased

Inhibiting $\subset$ Enhancing

Fig. 8 Cellular and molecular mechanisms underlying more efficient dimethyl fumarate-related reduction of EAE severity in male compared with female rats. The graphical scheme indicates that greater efficacy of $\mathrm{DMF}$ in reducing oxidative spinal cord (SC) tissue damage (judging by lower level of AOPP) in male compared with female rats reflects not only more pronounced direct stimulatory effects of DMF on anti-oxidant generation (associated with the increase in Nrf2 expression) followed by inhibitory effects on pro-oxidant generation (most likely due to suppression of NF-kB signaling pathway), but also its more prominent indirect effects, through favored polarization of SC myeloid cells (microglia/proinflammatory monocyte progeny) towards phagocyting

changes at myeloid cell level, the greater efficacy of DMF in impairing CD4+ T cell reactivation and possibly survival, and differentiation of highly pathogenic IFN- $\gamma+\mathrm{GM}-\mathrm{CSF}+\mathrm{IL}-17+$ T lymphocytes was found in males (Fig. 8). These diergisms at cell population level coupled with sex bias in DMF efficacy to enhance anti-oxidant defense through its action on Nrf2mediated expression of anti-oxidant genes contributed to lower SC oxidative stress in males (Fig. 8). To corroborate this notion is sex bias in the neuroprotective effects of some other anti-oxidants in rat model of hypoxia-ischemia-induced brain injury [90]. Additionally, the study supported our previous findings indicating that AOPP level may be used as a plasma marker to assess EAE activity and predict the response to therapy [7]. Overall, these findings, apart from fundamental importance for understanding sex bias in mechanisms determining the severity of neuroinflammation in EAE, and possibly MS, seem to be encouraging for sex/gender-based clinical studies aimed to optimize immunomodulatory/anti-oxidant therapy of MS taking into account patient's sex. The latter is important given that, sex-specific differences for some clinical
M2-like cells (CD163+ cells with upregulated Arg-1 expression), most possibly, with highly upregulated surface density of regulatory CD83 molecule (inhibits antigen presenting cell ability to activate CD4+ T lymphocytes leading to their diminished reactivation and survival) followed by diminished number of IL-17+ T lymphocytes, in particular highly pathogenic IFN- $\gamma+\mathrm{GM}-\mathrm{CSF}+$ ones (reflecting diminished CD4+ $\mathrm{T}$ cell reactivation and impaired polarization towards highly pathogenic IL-17+ cells because of downregulated expression of the key polarizing cytokines) due to stimulation of Nrf2 anti-inflammatory signaling pathway

outcomes in patients with MS who received the disease modifying therapies, including DMF, have occasionally been observed, but not systematically statistically analyzed to draw relevant conclusions [25].

\section{Compliance with Ethical Standards}

Funding This study was funded by the Ministry of Education, Science and Technological Development of Republic of Serbia (grant numbers 175050 and 175035).

Conflict of Interest The authors declare that they have no conflict of interest.

\section{References}

1. Smith KJ, Lassmann H (2002) The role of nitric oxide in multiple sclerosis. Lancet Neurol 1(4):232-241.doi:10.1016/S14744422(02)00102-3

2. Ciccarelli O, Barkhof F, Bodini B, De Stefano N, Golay X, Nicolay K, Pelletier D, Pouwels PJ et al (2014) Pathogenesis of multiple 
sclerosis: insights from molecular and metabolic imaging. Lancet Neurol 13(8):807-822. doi:10.1016/S1474-4422(14)70101-2

3. Hammann KP, Hopf HC (1986) Monocytes constitute the only peripheral blood cell population showing an increased burst activity in multiple sclerosis patients. Int Arch Allergy Appl Immunol 81(3):230-234. doi:10.1159/000234139

4. Koch MW, Ramsaransing GSM, Arutjunyan AV, Stepanov M, Teelken A, Heersema DJ, De Keyser J (2005) Oxidative stress in serum and peripheral blood leukocytes in patients with different disease courses of multiple sclerosis. J Neurol 253(4):483-487. doi:10.1007/s00415-005-0037-3

5. Nikić I, Merkler D, Sorbara C, Brinkoetter M, Kreutzfeldt M, Bareyre FM, Brück W, Bishop D et al (2011) A reversible form of axon damage in experimental autoimmune encephalomyelitis and multiple sclerosis. Nat Med 17(4):495-499. doi:10.1038/nm.2324

6. Van Horssen J, Witte ME, Schreibelt G, de Vries HE (2011) Radical changes in multiple sclerosis pathogenesis. Biochim Biophys Acta 1812(2):141-150. doi:10.1016/j.bbadis.2010.06.011

7. Dimitrijević M, Kotur-Stevuljević J, Stojić-Vukanić Z, Vujnović I, Pilipović I, Nacka-Aleksić M, Leposavić G (2017) Sex difference in oxidative stress parameters in spinal cord of rats with experimental autoimmune encephalomyelitis: relation to neurological deficit. Neurochem Res 42:481-492. doi:10.1007/s11064-016-2094-7

8. Croxford AL, Spath S, Becher B (2015) GM-CSF in neuroinflammation: licensing myeloid cells for tissue damage. Trends Immunol 36(10):651-662. doi:10.1016/j.it.2015.08.004

9. Linker RA, Lee DS, Ryan S, Van Dam AM, Conrad R, Bista P, Zeng W, Hronowsky X et al (2011) Fumaric acid esters exert neuroprotective effects in neuroinflammation via activation of the $\mathrm{Nrf} 2$ antioxidant pathway. Brain 134(3):678-692. doi:10.1093/brain/ awq386

10. Fox RJ, Miller DH, Phillips JT, Hutchinson M, Havrdova E, Kita M, Yang M, Raghupathi K et al (2012) CONFIRM study investigators, placebo-controlled phase 3 study of oral BG-12 or glatiramer in multiple sclerosis. N Engl J Med 367(12):10871097. doi:10.1056/nejmoa1206328

11. Gold R, Kappos L, Arnold DI, Bar-Or A, Giovannoni G, Selmaj K, Tornatore C, Sweetser MT et al (2012) DEFINE study investigators, placebo-controlled phase 3 study of oral BG-12 for relapsing multiple sclerosis. N Engl J Med 367(12):1098-1107. doi:10.1056/ nejmoa1114287

12. Schulze-Topphoff U, Varrin-Doyer M, Pekarek K, Spencer CM, Shetty A, Sagan SA, Cree BA, Sobel RA et al (2016) Dimethyl fumarate treatment induces adaptive and innate immune modulation independent of Nrf2. Proc Natl Acad Sci U S A 113(17):47774782. doi:10.1073/pnas.1603907113

13. Pitarokoili K, Ambrosius B, Meyer D, Schrewe L, Gold R (2015) Dimethyl fumarate ameliorates Lewis rat experimental autoimmune neuritis and mediates axonal protection. PLoS One 10(11): e0143416. doi:10.1371/journal.pone.0143416

14. Stoof TJ, Flier J, Sampat S, Nieboer C, Tensen CP, Boorsma DM (2001) The antipsoriatic drug dimethylfumarate strongly suppresses chemokine production in human keratinocytes and peripheral blood mononuclear cells. Br J Dermatol 144(6):1114-1120. doi:10.1046/ j.1365-2133.2001.04220.x

15. Gerdes S, Shakery K, Mrowietz U (2007) Dimethylfumarate inhibits nuclear binding of nuclear factor $\mathrm{kB}$ but not of nuclear factor of activated T cells and CCAAT/enhancer binding protein beta in activated human T cells. Br J Dermatol 156(5):838-842. doi:10. 1111/j.1365-2133.2007.07779.x

16. Nguyen T, Nioi P, Pickett CB (2009) The Nrf2-antioxidant response element signaling pathway and its activation by oxidative stress. J Biol Chem 284(20):13291-13295. doi:10.1074/jbc.r900010200

17. Scannevin RH, Chollate S, Jung MY, Shackett M, Patel H, Bista P, Zeng W, Ryan S et al (2012) Fumarates promote cytoprotection of central nervous system cells against oxidative stress via the nuclear factor (erythroid-derived 2)-like 2 pathway. J Pharmacol Exp Ther 341(1):274-284. doi:10.1124/jpet.111.190132

18. Gill AJ, Kolson DL (2013) Dimethyl fumarate modulation of immune and antioxidant responses: application to HIV therapy. Crit Rev Immunol 33(4):307-359. doi:10.1615/CritRevImmunol. 2013007247

19. Liu GH, Qu J, Shen X (2008) NF-kappaB/p65 antagonizes Nrf2ARE pathway by depriving CBP from Nrf2 and facilitating recruitment of HDAC3 to MafK. Biochim Biophy Acta 1783(5):713-727. doi:10.1016/j.bbamcr.2008.01.002

20. Bove R, Chitnis T (2013) Sexual disparities in the incidence and course of MS. Clin Immunol 149(2):201-210. doi:10.1016/j.clim. 2013.03.005

21. Giatti S, D'Intino G, Maschi O, Pesaresi M, Garcia-Segura LM, Calza L, Caruso D, Melcangi RC (2010) Acute experimental autoimmune encephalomyelitis induces sex dimorphic changes in neuroactive steroid levels. Neurochem Int 56(1):118-127. doi:10.1016/ j.neuint.2009.09.009

22. Nacka-Aleksić M, Djikić J, Pilipović I, Stojić-Vukanić Z, Kosec D, Bufan B, Arsenović-Ranin N, Dimitrijević M et al (2015) Male rats develop more severe experimental autoimmune encephalomyelitis than female rats: Sexual dimorphism and diergism at the spinal cord level. Brain Behav Immun 49:101-118. doi:10.1016/j.bbi.2015.04.017

23. Kawakami N, Lassmann S, Li Z, Odoardi F, Ritter T, Ziemssen T, Klinkert WE, Ellwart JW et al (2004) The activation status of neuroantigen-specific $\mathrm{T}$ cells in the target organ determines the clinical outcome of autoimmune encephalomyelitis. J Exp Med 199(2):185-197. doi:10.1084/jem.20031064

24. Zagni E, Simoni L, Colombo D (2016) Sex and gender differences in central nervous system-related disorders. Neurosci J 2016: 2827090. doi:10.1155/2016/2827090

25. Li R, Sun X, Shu Y, Mao Z, Xiao L, Qiu W, Lu Z, Hu X (2017) Sex differences in outcomes of disease-modifying treatments for multiple sclerosis: a systematic review. Mult Scler Relat Dis 12:23-28. doi:10.1016/j.msard.2017.01.001

26. Bar-Or A, Gold R, Kappos L, Arnold DL, Giovannoni G, Selmaj K, O'Gorman J, Stephan M et al (2013) Clinical efficacy of BG-12 (dimethyl fumarate) in patients with relapsing-remitting multiple sclerosis: subgroup analyses of the DEFINE study. J Neurol 260: 2297-2305. doi:10.1007/s00415-013-6954-7

27. Hutchinson M, Fox RJ, Miller DH, Phillips JT, Kita M, Havrdova E, O'Gorman J, Zhang R et al (2013) Clinical efficacy of BG-12 (dimethyl fumarate) in patients with relapsing-remitting multiple sclerosis: subgroup analyses of the CONFIRM study. J Neurol 260:2286-2296. doi:10.1007/s00415-013-6968-1

28. Djikić J, Nacka-Aleksić M, Pilipović I, Stojić-Vukanić Z, Bufan B, Kosec D, Dimitrijević M, Leposavić G (2014) Age-associated changes in rat immune system: Lessons learned from experimental autoimmune encephalomyelitis. Exp Gerontol 58:179-197. doi:10. 1016/j.exger.2014.08.005

29. Ridderstad Wollberg A, Ericsson-Dahlstrand A, Juréus A, Ekerot P, Simon S, Nilsson M, Wiklund S-J, Berg A-L et al (2014) Pharmacological inhibition of the chemokine receptor CX3CR1 attenuates disease in a chronic-relapsing rat model for multiple sclerosis. PNAS 111(14):5409-5414. doi:10.1073/pnas.1316510111

30. Dimitrijević M, Aleksić I, Vujić V, Stanojević S, Pilipović P, von Hörsten S, Leposavić G (2014) Peritoneal exudate cells from longlived rats exhibit increased IL-10/IL-1 $\beta$ expression ratio and preserved NO/urea ratio following LPS-stimulation in vitro. Age (Dordr) 36(4):9696. doi:10.1007/s11357-014-9696-2

31. Auclair C, Voisin E (1985) Nitroblue tetrazolium reduction. In: Greenwald RA (ed) CRC handbook of methods for oxygen radical research. CRC Press, Boca Raton, pp. 123-132

32. Misra HP, Fridovich I (1972) The role of superoxide anion in the autoxidation of epinephrine and a simple assay for superoxide dismutase. J Biol Chem 247(10):3170-3175 
33. Girotti MJ, Khan N, McLellan BA (1991) Early measurement of systemic lipid peroxidation products in the plasma of major blunt trauma patients. J Trauma 31(1):32-35. doi:10.1097/00005373199101000-00007

34. Witko-Sarsat V, Friedlander M, Capeillère-Blandin C, NguyenKhoa T, Nguyen AT, Zingraff J, Jungers P, Descamps-Latscha B (1996) Advanced oxidation protein products as a novel marker of oxidative stress in uremia. Kidney Int 49(5):1304-1313. doi:10. 1038/ki.1996.186

35. Erel O (2005) A new automated colorimetric method for measuring total oxidant status. Clin Biochem 38(12):1103-1111. doi:10.1016/ j.clinbiochem

36. Kotur-Stevuljevic J, Bogavac-Stanojevic N, Jelic-Ivanovic Z, Stefanovic A, Gojkovic T, Joksic J, Sopic M, Gulan B et al (2015) Oxidative stress and paraoxonase 1 status in acute ischemic stroke patients. Atherosclerosis 241(1):192-198. doi:10.1016/j. atherosclerosis.2015.05.016

37. Erel O (2004) A novel automated direct measurement method for total antioxidant capacity using a new generation, more stable ABTS radical cation. Clin Biochem 37(4):277-285. doi:10.1016/ j.clinbiochem.2003.11.015

38. Alamdari DH, Paletas K, Pegiou T, Sarigianni M, Befani C, Koliakos G (2007) A novel assay for the evaluation of the prooxidant-antioxidant balance, before and after antioxidant vitamin administration in type II diabetes patients. Clin Biochem 40(34):248-254. doi:10.1016/j.clinbiochem.2006.10.017

39. Bradford MM (1976) A rapid and sensitive method for the quantitation of microgram quantities of protein utilizing the principle of protein-dye binding. Anal Biochem 72:248-254

40. Fillmore PD, Blankenhorn EP, Zachary JF, Teuscher C (2004) Adult gonadal hormones selectively regulate sexually dimorphic quantitative traits observed in experimental allergic encephalomyelitis. Am J Pathol 164(1):167-175. doi:10.1016/S0002-9440(10) 63107-0

41. Damsker JM, Hansen AM, Caspi RR (2010) Th1 and Th17 cells: adversaries and collaborators. Ann N Y Acad Sci 1183:211-221. doi:10.1111/j.1749-6632.2009.05133.x

42. Flügel A, Berkowicz T, Ritter T, Labeur M, Jenne DE, Li Z, Ellwart JW, Willem M et al (2001) Migratory activity and functional changes of green fluorescent effector cells before and during experimental autoimmune encephalomyelitis. Immunity 14(5):547-560. doi:10. 1016/S1074-7613(01)00143-1

43. Treumer F, Zhu K, Gläser R, Mrowietz U (2003) Dimethylfumarate is a potent inducer of apoptosis in human T cells. J Invest Dermatol 121(6):1383-1388. doi:10.1111/j.1523-1747.2003.12605.x

44. Codarri L, Gyülvészi G, Tosevski V, Hesske L, Fontana A, Magnenat L, Suter T, Becher B (2011) ROR $\gamma$ t drives production of the cytokine GM-CSF in helper T cells, which is essential for the effector phase of autoimmune neuroinflammation. Nat Immunol 12(6):560-567. doi:10.1038/ni.2027

45. El-Behi M, Ciric B, Dai H, Yan Y, Cullimore M, Safavi F, Zhang GX, Dittel BN et al (2011) The encephalitogenicity of $\mathrm{T}(\mathrm{H}) 17$ cells is dependent on IL-1- and IL-23-induced production of the cytokine GM-CSF. Nat Immunol 12(6):568-575. doi:10.1038/ni.2031

46. Stojić-Vukanić Z, Pilipović I, Vujnović I, Nacka-Aleksić M, Petrović R, Arsenović-Ranin N, Dimitrijević M, Leposavić G (2016) GM-CSF-producing Th cells in rats sensitive and resistant to experimental autoimmune encephalomyelitis. PLoS One 11(11): e0166498. doi:10.1371/journal.pone.0166498

47. Ghoreschi K, Laurence A, Yang XP, Tato CM, McGeachy MJ, Konkel JE, Ramos HL, Wei L et al (2010) Generation of pathogenic $\mathrm{T}(\mathrm{H}) 17$ cells in the absence of TGF- $\beta$ signalling. Nature 467(7318):967-971. doi:10.1038/nature09447

48. Mosser DM, Edwards JP (2008) Exploring the full spectrum of macrophage activation. Nat Rev Immunol 8(12):958-969. doi:10. 1038/nri2448
49. Gandhi R, Laroni A, Weiner HL (2010) Role of the innate immune system in the pathogenesis of multiple sclerosis. J Neuroimmunol 221(1-2):7-14. doi:10.1016/j.jneuroim.2009.10.015

50. Murphy AC, Lalor SJ, Lynch MA, Mills KH (2010) Infiltration of Th1 and Th17 cells and activation of microglia in the CNS during the course of experimental autoimmune encephalomyelitis. Brain Behav Immun 24(4):641-651. doi:10.1016/j.bbi.2010.01.014

51. Han R, Xiao J, Zhai H, Hao J (2016) Dimethyl fumarate attenuates experimental autoimmune neuritis through the nuclear factor erythroid-derived 2-related factor 2/hemoxygenase-1 pathway by altering the balance of M1/M2 macrophages. J Neuroinflammation 13(1):97. doi:10.1186/s12974-016-0559-x

52. Bullard DC, Hu X, Schoeb TR, Axtell RC, Raman C, Barnum SR (2005) Critical requirement of CD11b (Mac-1) on T cells and accessory cells for development of experimental autoimmune encephalomyelitis. J Immunol 175(10):6327-6333. doi:10.4049/ jimmunol.175.10.6327

53. Mindur JE, Ito N, Dhib-Jalbut S, Ito K (2014) Early treatment with anti-VLA-4 mAb can prevent the infiltration and/or development of

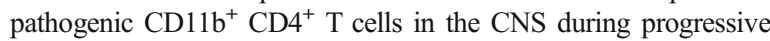
EAE. PLoS One 9(6):e99068. doi:10.1371/journal.pone.0099068

54. Zhang Z, Zhang ZY, Schittenhelm J, Wu Y, Meyermann R, Schluesener HJ (2011) Parenchymal accumulation of CD163+ macrophages/ microglia in multiple sclerosis brains. J Neuroimmunol 237(1-2):7379. doi:10.1016/j.jneuroim.2011.06.006

55. Fehr E-M, Kierschke S, Max R, Gerber A, Lorenz H-M, Schiller M (2009) Apototic cell-derived membrane vesicles induce CD83 expression on human mdDC. Autoimmunity 42(4):322-324. doi:10. 1080/08916930902832173

56. Stöger JL, Goossens P, de Winther MP (2010) Macrophage heterogeneity: relevance and functional implications in atherosclerosis. Curr Vasc Pharmacol 8(2):233-248. doi:10.2174/ 157016110790886983

57. Munder M, Eichmann K, Morán JM, Centeno F, Soler G, Modolell M (1999) Th1/Th2-regulated expression of arginase isoforms in murine macrophages and dendritic cells. J Immunol 163(7):37713777

58. Cherry JD, Olschowka JA, O'Banion MK (2014) Neuroinflammation and M2 microglia: the good, the bad, and the inflamed. J Neuroinflammation 11:98. doi:10.1186/17422094-11-98

59. Ahn M, Yang W, Kim H, Jin JK, Moon C, Shin T (2012) Immunohistochemical study of arginase-1 in the spinal cords of Lewis rats with experimental autoimmune encephalomyelitis. Brain Res 1453:77-86. doi:10.1016/j.brainres.2012.03.023

60. Mattila JT, Ojo OO, Kepka-Lenhart D, Marino S, Kim JH, Eum SY, Via LE, Barry CE 3rd et al (2013) Microenvironments in tuberculous granulomas are delineated by distinct populations of macrophage subsets and expression of nitric oxide synthase and arginase isoforms. J Immunol 191(2):773-784. doi:10.4049/jimmunol. 1300113

61. Honorat A, Kinoshita M, Okuno T, Takata K, Koda T, Tada S, Shirakura T, Fujimura H et al (2013) Xanthine oxidase mediates axonal and myelin loss in a murine model of multiple sclerosis. PLoS One 8:e71329. doi:10.1371/journal.pone.0071329

62. Fukai T, Ushio-Fukai M (2011) Superoxide dismutases: role in redox signaling, vascular function, and diseases. Antioxid Redox Signal 15(6):1583-1606. doi:10.1089/ars.2011.3999

63. Huang H, Taraboletti A, Shriver LP (2015) Dimethyl fumarate modulates antioxidant and lipid metabolism in oligodendrocytes. Redox Biol 5:169-175. doi:10.1016/j.redox.2015.04.011

64. Chen H, Assmann JC, Krenz A, Rahman M, Grimm M, Karsten CM, Köhl J, Offermanns S et al (2014) Hydrocarboxylic acid receptor 2 mediates dimethyl fumarate's protective effect in EAE. J Clin Invest 124(5):2188-21192. doi:10.1172/JCI72151 
65. Lim JL, Van der Pol SMA, Di Dio F, Van het Hof B, Kooij G, De Vries HE, Van Horssen J (2016) Protective effects of monomethyl fumarate at the inflamed blood-brain barrier. Microvasc Res 105: 61-69. doi:10.1016/j.mvr.2015.12.003

66. Wang L-F, Yokoyama KK, Lin C-L, Chen T-Y, Hsiao H-W, Chiang P-C, Hsu C (2016) Knockout of ho-1 protects the striatum from ferrous iron-induced injury in a male-specific manner in mice. Sci Reports 6:26358. doi:10.1038/srep26358

67. Rohrer PR, Rudraiah S, Goedken MJ, Manautou JE (2014) Is nuclear factor erythroid 2-related factor 2 responsible for sex differences in susceptibility to acetaminophen-induced hepatotoxicity in mice? Drug Metab Dispos 42(10):1663-1674. doi:10.1124/dmd. 114.059006

68. Kratschmar DV, Calabrese D, Walsh J, Lister A, Birk J, AppenzellerHerzog C, Moulin P, Goldring CE et al (2012) Suppression of the Nrf2-dependent antioxidant response by glucocorticoids and $11 \beta$ HSD1-mediated glucocorticoid activation in hepatic cells. PLoS One 7(5):e36774. doi:10.1371/journal.pone.0036774

69. Rubant SA, Ludwig RJ, Diehl S, Hardt K, Kaufmann R, Pfeilschifter JM, Boehncke WH (2008) Dimethylfumarate reduces leukocyte rolling in vivo through modulation of adhesion molecule expression. J Invest Dermatol 128(2):326-331. doi:10.1038/sj.jid. 5700996

70. Wallbrecht K, Drick N, Hund AC, Schon MP (2011) Downregulation of endothelial adhesion molecules by dimethylfumarate, but not monomethylfumarate, and impairment of dynamic lymphocyte-endothelial cell interactions. Exp Dermatol 20(12):980-985. doi:10.1111/j.1600-0625.2011.01376.x

71. Dehmel T, Dobert M, Pankratz S, Leussink VI, Hartung HP, Wiendl H, Kieseier BC (2014) Monomethylfumarate reduces in vitro migration of mononuclear cells. Neurol Sci 35(7):1121-1125. doi:10. 1007/s10072-014-1663-2

72. Zhao X, Eghbali-Webb M (2002) Gender-related differences in basal and hypoxia-induced activation of signal transduction pathways controlling cell cycle progression and apoptosis, in cardiac fibroblasts. Endocrine 18(2):137-145. doi:10.1385/ENDO:18:2: 137

73. Ritzel RM, Capozzi LA, McCullough LD (2013) Sex, stroke, and inflammation: the potential for estrogen-mediated immunoprotection in stroke. Horm Behav 63(2):238-253. doi:10. 1016/j.yhbeh.2012.04.007

74. Ebihara S, Tajima H, Ono M (2016) Nuclear factor erythroid 2related factor 2 is a critical target for the treatment of glucocorticoid-resistant lupus nephritis. Arthritis Res Ther 18(1): 139. doi:10.1186/s13075-016-1039-5

75. Kopf M, Ruedl C, Schmitz N, Gallimore A, Lefrang K, Ecabert B, Odermatt B, Bachmann MF (1999) OX40-deficient mice are defective in Th cell proliferation but are competent in generating B cell and CTL responses after virus infection. Immunity 11(6):699-708. doi:10.1016/S1074-7613(00)80144-2

76. Fujimoto Y, Tedder TF (2006) CD83: a regulatory molecule of the immune system with great potential for therapeutic application. $\mathrm{J}$ Med Dent Sci 53(2):85-91

77. Hock BD, Kato M, McKenzie JL, Hart DN (2001) A soluble form of $\mathrm{CD} 83$ is released from activated dendritic cells and $\mathrm{B}$ lymphocytes, and is detectable in normal human sera. Int Immunol 13(7):959-967. doi:10.1093/intimm/13.7.959

78. Lechmann M, Krooshoop DJ, Dudziak D, Kremmer E, Kuhnt C, Figdor CG, Schuler G, Steinkasserer A (2001) The extracellular domain of CD83 inhibits dendritic cell-mediated T cell stimulation and binds to a ligand on dendritic cells. J Exp Med 194(12):1813-1821

79. Sénéchal B, Boruchov AM, Reagan JL, Hart DN, Young JW (2004) Infection of mature monocyte-derived dendritic cells with human cytomegalovirus inhibits stimulation of T-cell proliferation via the release of soluble CD83. Blood 103(11):4207-4215. doi:10.1182/ blood-2003-12-4350

80. Zinser E, Lechmann M, Golka A, Lutz MB, Steinkasserer A (2004) Prevention and treatment of experimental autoimmune encephalomyelitis by soluble CD83. J Exp Med 200(3):345-351. doi:10. 1084/jem.20030973

81. Bates JM, Flanagan K, Mo L, Ota N, Ding J, Ho S, Liu S, RooseGirma M et al (2015) Dendritic cell CD83 homotypic interactions regulate inflammation and promote mucosal homeostasis. Mucosal Immunol 8(2):414 428. doi:10.1038/mi.2014.79

82. Ghoreschi K, Bruck J, Kellerer C, Deng C, Peng H, Rothfuss O, Hussain RZ, Gocke AR et al (2011) Fumarates improve psoriasis and multiple sclerosis by inducing type II dendritic cells. J Exp Med 208(11):2291-2303. doi:10.1084/jem.20100977

83. Morgan MJ, Liu ZG (2011) Crosstalk of reactive oxygen species and NF-KB signaling. Cell Res 21(1):103-115. doi:10.1038/cr. 2010.178

84. Mühl H, Bachmann M, Pfeilschifter J (2011) Inducible NO synthase and antibacterial host defence in times of Th17/Th22/T22 immunity. Cell Microbiol 13(3):340-348. doi:10.1111/j.14625822.2010.01559.x

85. Bonacasa B, Perez C, Salom MG, Lopez B, Saez-Belmonte F, Martinez P, Casas T, Fenoy FJ et al (2013) Sexual dimorphism in renal heme-heme oxygenase system in the streptozotocin diabetic rats. Curr Pharm Des 19(15):2678-2686. doi:10.2174/ 1381612811319150002

86. Schmidt TJ, Ak M, Mrowietz U (2007) Reactivity of dimethyl fumarate and methylhydrogen fumarate towards glutathione and $\mathrm{N}$-acetyl-L-cysteine-preparation of S-substituted thiosuccinic acid esters. Bioorg Med Chem 15(1):333-342. doi:10.1016/j.bmc.2006. 09.053

87. Stein DG (2001) Brain damage, sex hormones and recovery: a new role for progesterone and estrogen. Trends Neurosci 24(7):386391. doi:10.1016/S0166-2236(00)01821-X

88. Penaloza C, Estevez B, Orlanski S, Sikorska M, Walker R, Smith C, Smith B, Lockshin RA et al (2009) Sex of the cell dictates its response: Differential gene expression and sensitivity to cell death inducing stress in male and female cells. FASEB J 23(6):1869 1879. doi:10.1096/fj.08-119388

89. Cichocki JA, Smith GJ, Mendoza R, Buckpitt AR, Van Winkle LS, Morris JB (2014) Sex differences in the acute nasal antioxidant/ antielectrophilic response of the rat to inhaled naphthalene. Toxicol Sci 139(1):234-244. doi:10.1093/toxsci/kfu031

90. Nie X, Lowe DW, Rollins LG, Bentzley J, Fraser JL, Martin R, Singh I, Jenkins D (2016) Sex-specific effects of N-acetylcysteine in neonatal rats treated with hypothermia after severe hypoxia-ischemia. Neurosci Res 108:24-33. doi:10.1016/j.neures.2016.01.008 